\title{
PET Molecular Imaging: A Holistic Review of Current Practice and Emerging Perspectives for Diagnosis, Therapeutic Evaluation and Prognosis in Clinical Oncology
}

\author{
Valentin Duclos ${ }^{1, \dagger}{ }^{,}$Alex Iep ${ }^{1,+}{ }^{,}$Léa Gomez ${ }^{1}$, Lucas Goldfarb ${ }^{2}$ and Florent L. Besson $1,3,4, *$ (i) \\ 1 Department of Biophysics and Nuclear Medicine-Molecular Imaging, Hôpitaux Universitaires Paris Saclay, \\ Assistance Publique-Hôpitaux de Paris, CHU Bicêtre, 94270 Le Kremlin-Bicêtre, France; \\ duclos.valentin@icloud.com (V.D.); alexiep@ymail.com (A.I.); lea.gomez@aphp.fr (L.G.) \\ 2 Service Hospitalier Frédéric Joliot-CEA, 91401 Orsay, France; lucas.goldfarb@cea.fr \\ 3 Université Paris Saclay, CEA, CNRS, Inserm, BioMaps, 91401 Orsay, France \\ 4 School of Medicine, Université Paris Saclay, 94720 Le Kremlin-Bicêtre, France \\ * Correspondence: florent.besson@aphp.fr \\ + These authors contributed equally to this work.
}

check for updates

Citation: Duclos, V.; Iep, A.; Gomez, L.; Goldfarb, L.; Besson, F.L. PET Molecular Imaging: A Holistic Review of Current Practice and Emerging Perspectives for Diagnosis, Therapeutic Evaluation and Prognosis in Clinical Oncology. Int. J. Mol. Sci. 2021, 22, 4159. https:// doi.org/10.3390/ijms22084159

Academic Editor: Giorgio Treglia

Received: 3 April 2021

Accepted: 15 April 2021

Published: 16 April 2021

Publisher's Note: MDPI stays neutral with regard to jurisdictional claims in published maps and institutional affiliations.

Copyright: (c) 2021 by the authors. Licensee MDPI, Basel, Switzerland. This article is an open access article distributed under the terms and conditions of the Creative Commons Attribution (CC BY) license (https:/ / creativecommons.org/licenses/by/ $4.0 /)$.

\begin{abstract}
PET/CT molecular imaging has been imposed in clinical oncological practice over the past 20 years, driven by its two well-grounded foundations: quantification and radiolabeled molecular probe vectorization. From basic visual interpretation to more sophisticated full kinetic modeling, PET technology provides a unique opportunity to characterize various biological processes with different levels of analysis. In clinical practice, many efforts have been made during the last two decades to standardize image analyses at the international level, but advanced metrics are still under use in practice. In parallel, the integration of PET imaging with radionuclide therapy, also known as radiolabeled theranostics, has paved the way towards highly sensitive radionuclide-based precision medicine, with major breakthroughs emerging in neuroendocrine tumors and prostate cancer. PET imaging of tumor immunity and beyond is also emerging, emphasizing the unique capabilities of PET molecular imaging to constantly adapt to emerging oncological challenges. However, these new horizons face the growing complexity of multidimensional data. In the era of precision medicine, statistical and computer sciences are currently revolutionizing image-based decision making, paving the way for more holistic cancer molecular imaging analyses at the whole-body level.
\end{abstract}

Keywords: PET; quantification; molecular imaging; theranostics; multimodality; computer science

\section{Introduction}

Awarded the medical invention of the year by Time Magazine in 2000, PET/CT molecular imaging has been imposed in clinical oncological practice over the past 20 years, substantially modifying the management of many cancer subtypes in daily practice [1-3]. Supported by the International Atomic Energy Agency, the Lancet Oncology commission on medical imaging and nuclear medicine-an international consortium established in 2018 to inventory and promote access to imaging and nuclear medicine for cancer care-has emphasized the substantial health and cost benefits of scaling up access to imaging and nuclear medicine for cancer care worldwide [4]. In particular, PET/CT and theranostics are now recommended imaging modalities for cancer care in tertiary health care centers.

Based on the well-grounded foundations of quantification and radiolabeled molecular probe vectorization, the goal of this article is to provide a holistic overview of the capabilities, current practice and emerging perspective of PET-molecular imaging for diagnosis, therapeutic evaluation and prognosis in clinical oncology. 


\section{PET Molecular Imaging: A Powerful Quantitative Imaging Tool with Different Levels of Analysis}

PET imaging was mainly developed in the 1970s for brain research purposes. In the early 2000s, PET/CT hybrid imaging was rapidly imposed worldwide as a critical oncological imaging tool, paving the way for the molecular imaging-based assessment of tumors in clinical practice. During the last 20 years, constant technical improvements have led to a 3- to 5-fold decrease in injected radioactivity in clinical practice, making the debate on radiation exposure clearly outdated in view of the major benefit obtained in daily patient care. The recent FDA-cleared and CE-marked deep learning solutions that provide dose-reduced AI-based FDG PET/CT should optimize patients' radiation exposure even more in the future (SubtlePET $\left.{ }^{\mathrm{TM}} \mathrm{AI}[5]\right)$. With its very high detection sensitivity properties (picomolar, $10^{6}$ higher than standard morphological imaging), PET is a powerful imaging tool that can be used to quantify various biological processes. By quantification, one must understand a simple linear relationship between the numerical pixel value $N$ measured in a region of interest (ROI) of the image and the biological radiotracer concentration $[C]$ in the related tissue structure: $N=k[C]$. Importantly, this fundamental property depends on the control of many technical and physical factors to make an optimized and accurate link between the patient and its related optimized PET imaging data [6]. Regular quality controls, standardized practical procedures and CT-based attenuation corrections are among the most important prerequisites. Additionally, one must be aware of the impact of image reconstruction parameters on the measured PET data. For these reasons, the European Association of Nuclear Medicine (EANM) launched the EANM Research GmbH (EARL) initiative in 2006 to promote the standardization of PET practices (clinical and research) at the international level [7]. In the same way, and because molecular imaging is impacted by the patient's physiological condition, several drug intakes, fasting procedures and delay times between the radiotracer injection and the image acquisition must be verified. Therefore, numerous international guidelines have been published to standardize these procedures [8-10]. For example, considering FDG PET imaging, the most widely used PET radiotracer in clinical oncology, and because tumor glucose metabolism increases with time [11], a fixed 60-min delay time between radiotracer injection and PET acquisition has been defined [8]. Additionally, metabolism-modifying drugs such as G-CSF and physical activity must be avoided, and a 6-h fast before and euglycemia at the time of image acquisition must be verified [8]. Based on these important technical considerations, several levels of quantification have been historically developed for PET imaging: from visual interpretation to full kinetic modeling, the level of information provided to the clinician is not the same and does not require the same acquisition procedures (Figure 1). 


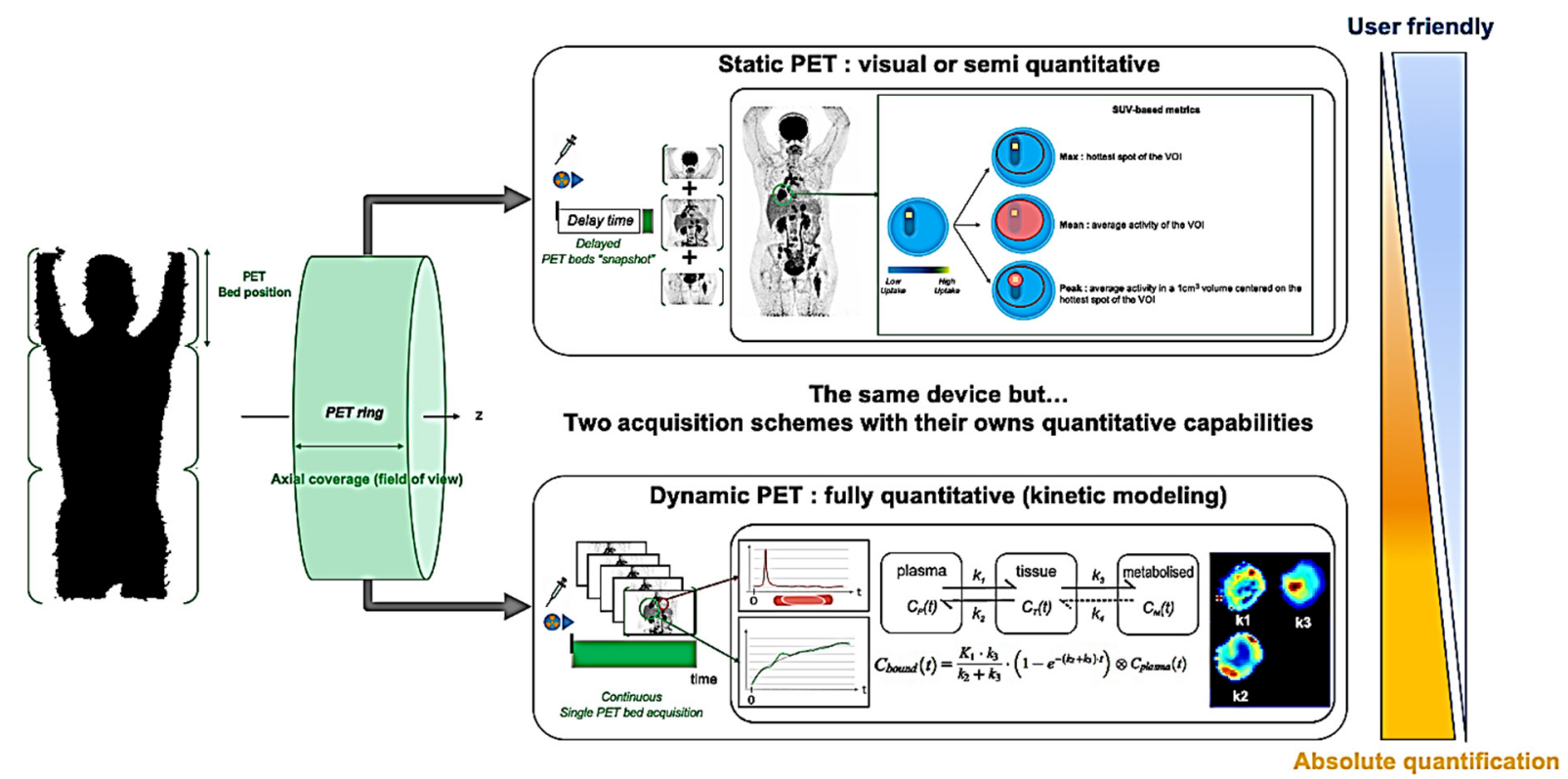

Figure 1. Main concepts of image acquisition and quantification in PET. The image coverage (PET bed position) depends on the axial field of view of the PET ring. Two acquisition schemes may be performed: the static mode (top panel), massively used in current practice, consists of acquiring snapshots of each PET bed position successively (a few minutes per bed position) at a fixed delay time after radiotracer injection (60 min in oncology), and the dynamic mode (bottom panel), currently devoted mainly to research purposes, consists of acquiring a PET bed position continuously (from a few minutes to one hour depending on the mathematical model used). The arterial input function (red curve) and lesion time-activity curve (green curve) are measured from volumes of interest, fitted to mathematical models to generate parametric maps of the lesion of biological significance (perfusion, enzymatic activity, metabolic rate of glucose consumption, etc.). While the static acquisition scheme is fast and user friendly, only visual and SUV-based semiquantitative metrics can be generated. However, dynamic PET models provide advanced quantitative metrics of sophisticated biological significance and remain the absolute reference standard for quantification.

\subsection{Visual Analysis}

This first level of analysis only requires static PET imaging data (the standard of care in clinical practice): the radiotracer is injected intravenously into the patient, and a few minutes of PET acquisitions (typically 2 to $5 \mathrm{~min}$ per bed position, which is defined by the PET axial field of view) are started after a fixed delay time from the injection (e.g., $60 \mathrm{~min}$ for ${ }^{18} \mathrm{~F}-\mathrm{FDG}$ ). The resulting PET imaging data are, thus, an average snapshot of the entire acquisition time for each PET bed position (Figure 1). Visual analysis considers any non-physiological radiotracer uptake as abnormal. Although this protocol is very simple to use, accurate knowledge of radiotracer biodistributions is required (Figure 2). Additionally, this pattern-based approach is subjective and remains purely qualitative. To reduce the inter- and intraindividual variabilities, visual grade normalizations to reference regions have been proposed (cf infra). The diagnostic and prognostic capabilities of PET visual analyses over conventional imaging are perfectly illustrated in FDG-avid lymphoma patients [12], with reported management changes up to $45 \%$ at initial staging [13] and improved outcome prediction (both progression and event-free survival) at both early and end-of-treatment evaluations (for extensive review, please refer to Appendices A1-A3 of [12]). In the same way, other well-grounded illustrative foundations emphasizing the high suitability of visual-based PET assessments for the diagnosis or management of oncological patients include malignant melanoma [14], non-lepidic non-small-cell lung cancer $\left({ }^{18} \mathrm{~F}-\mathrm{FDG}\right)[1,15,16]$, paraganglioma syndromes $\left({ }^{18} \mathrm{~F}-\mathrm{FDOPA}\right.$ for SDHC, SDHD and SDHAF2 gene mutations) [17-19] or, more recently, multiple myeloma [20]. 


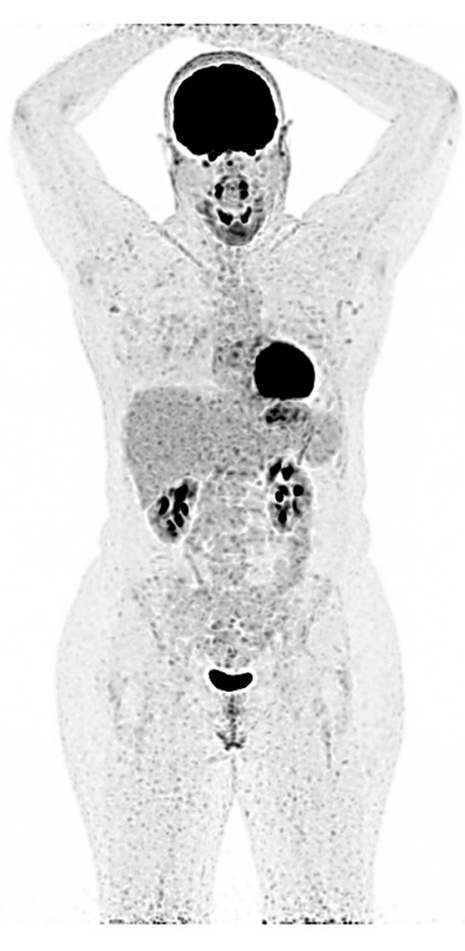

${ }^{18}$ F-FDG

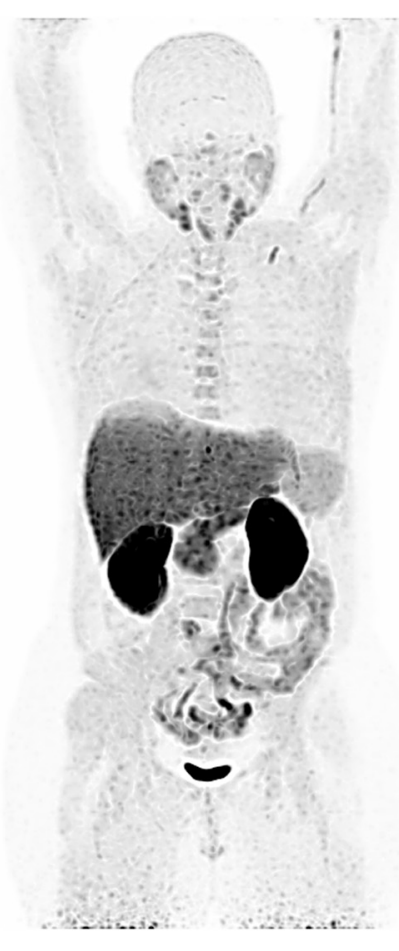

${ }^{18} \mathrm{~F}$-Choline

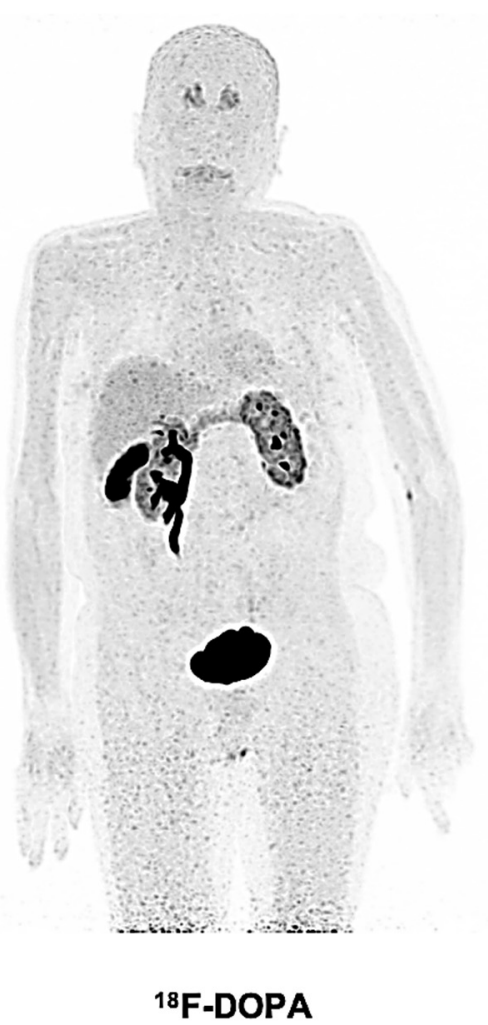

${ }^{18}$ F-DOPA

Figure 2. Normal biodistributions of three widely used PET radiotracers in oncological practice (static PET acquisitions): ${ }^{18} \mathrm{~F}$-FDG to assess glucose metabolism, ${ }^{18} \mathrm{~F}$-choline to assess membrane renewal and ${ }^{18} \mathrm{~F}$-FDOPA to assess the metabolism of L-DOPA. In the three cases, the radiotracer physiological biodistributions have their own characteristics.

\subsection{Semi-Quantitative Analyses}

To measure the biological aggressiveness of tumors and to monitor the response to treatment from standard-of-care static PET imaging data with more objective metrics, semiquantitative approaches have been increasingly used in clinical studies. The standardized uptake value (SUV), the most widely used semi-quantitative PET metric that was first used in the 1980s [21], is a unitless parameter defined by the ratio of the time-decay-corrected radioactivity concentration measured in a region of interest $\left(C_{\text {target }}\right.$, in $\left.\mathrm{MBq} / \mathrm{mL}\right)$ to the radioactivity injected in the body $\left(C_{\text {injected }}\right.$, in $\left.\mathrm{MBq}\right)$, normalized by the body weight (in g) or equivalent: $S U V b w=\frac{C_{\text {target }}}{C_{\text {injected }} / \text { Weight }} \times 1 \mathrm{~g} / \mathrm{mL}$. SUV normalization to body surface area $\left(\mathrm{SUV}_{\mathrm{bsa}}\right)$ or, more recently, lean body mass $\left(\mathrm{SUV}_{\mathrm{lbm}}\right.$ or $\left.\mathrm{SUL}\right)$ instead of body weight, has been proposed, and SUL is the current preferred metric for response assessment studies because of its lower dependency on body weight changes [8]. From this general concept, many SUV-based metrics have been reported since the 1990s, including SUV $\max$ (the maximum pixel activity measured in the region of interest), $\mathrm{SUV}_{\text {mean }}$ (the mean of pixel activities measured in the region of interest) or $\mathrm{SUV}_{\text {peak }}$ (the mean of pixel activities measured in a volume of $1 \mathrm{~cm}^{3}$ centered on the higher uptake part of the region of interest), but also target background SUV ratios $\left(\mathrm{SUV}_{\mathrm{r}}\right)$ and composite whole-body scores, such as metabolic tumor volume (TV $=\sum_{1}^{n}\left(\right.$ Volume $\left._{n}\right)$ for $n$ lesions identified at the whole-body level) or total lesion glycolysis (TLG $=\sum_{1}^{n}\left(S U V_{\text {mean }} n \times V_{\text {Volume }}\right)$ for $n$ lesions identified at the whole-body level) (Figure 3). Importantly, all these SUV-based metrics intrinsically depend on numerous physical and technical factors [22,23], strongly limiting the absolute comparability at the multicenter level except if using proper standardization procedures [7]. Additionally, the semiautomated segmentation procedures used to generate metabolic volumes of interest are still mainly based on simple fixed thresholds in clinical practice (typically $3 \mathrm{D}$ isocontour at $41 \%$ or $50 \%$ of the maximum pixel value) [8], despite their well-known inaccuracy to delineate heterogeneous tumor lesions. The segmentation task is 
an entire research topic in itself, illustrating the richness of the many possibilities developed in this field [24]. In general, SUV-based metrics and derivatives have shown their relevance for early response assessments of treatment or prognosis in various malignancies, such as gastric cancer [25], rectal cancer [26], lymphoma [27-30], gastrointestinal stromal tumors (GISTs) [31,32] or multiple myeloma [33,34].

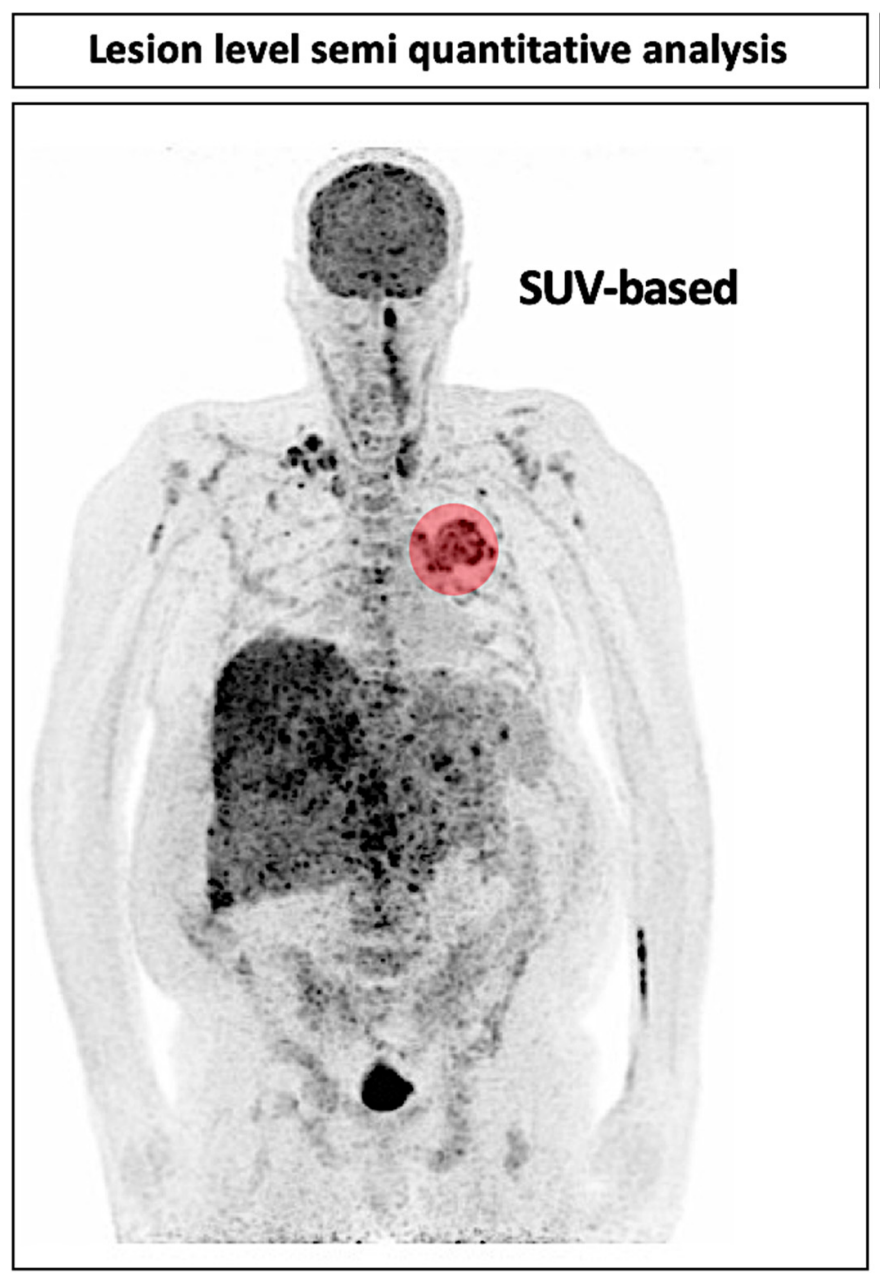

\section{Whole-body level semi quantitative analysis}

Figure 3. Semiquantitative PET metrics can be extracted at the lesion level (left panel, ${ }^{18}$ F-FDG PET scan of a patient with NSCLC) or at the whole-body level (right panel, ${ }^{68} \mathrm{Ga}$-PSMA PET scan of a patient with prostate cancer, courtesy of Jérémie Calais and Andrei Gafita, Ahmanson Translational Theranostics Division, UCLA, Los Angeles, CA, USA). For whole body metrics, the sum of each SUV-based metric extracted at the lesion level is used: metabolic tumor volume (MTV) or total volume (TV) is defined at a fixed SUV threshold (typically $40 \%$ or $50 \%$ of SUV max in standard practice), and total lesion glycolysis (TLG) is defined as MTV $\times \mathrm{SUV}_{\text {mean. }}$ MTV and TLG are surrogates of tumor burden at the whole-body level.

\subsection{Kinetic Modeling}

In fact, visual and semi-quantitative PET metrics derived from static PET images provide limited information. Using dynamic PET acquisitions provides more sophisticated metrics, allowing the quantification of advanced metabolic pathways at the cellular level (Figure 1). From Patlak simplified graphical analysis [35] to full compartmental analyses $(1,2,3$ or more compartments depending on the estimated biological function: perfusion, enzymatic activity, receptor binding) [36], PET kinetic modeling is considered the reference standard for absolute quantification. Compared to standard-of-care PET static measurements, dynamic PET metrics have provided promising results to improve the diagnosis, response assessment or prognosis of various malignancies [37]. To date, historical drawbacks have limited its use in clinical practice. In particular, the need for time-consuming 
acquisition schemes (up to one-hour continuous PET acquisition to estimate the full compartmental modeling of glucose metabolism [38]), the very limited axial coverage of the body extent in standard-of-care PET/CT devices and the complexity of image processing remain major limiting factors. However, the recent FDA clearances of large axial coverage and total body PET/CT systems [39-41], together with potential time-reduced acquisition procedures [42,43], improved reconstructions and postprocessing tools, will probably democratize dynamic whole-body PET in research and clinical practice, boosted by the growing molecular targeting requirements related to oncological drug development [44].

\section{PET Molecular Imaging: Response Evaluation Criteria in Practice}

The use of robust, easy-to-use and reliable interpretation criteria is of particular importance in oncological imaging. In clinical practice, many efforts have been made over the last two decades to standardize image analyses at an international level. Supported by historical RECIST morphological-based models, the response criteria are traditionally defined by four main categories: complete response (CR), partial response (PR), stable disease (SD) or progressive disease (PD). Although RECIST and its revised versions historically dominate this field in clinical trials [45], its limitations in predicting survival outcome or response to treatments and the massive deployment of PET imaging in worldwide oncological practice have motivated the emergence of PET-based response criteria in many cancer diseases. Depending of the targeted disease, several PET-based international criteria have been proposed as described in the next sections.

\subsection{Solid Tumors}

A general historic of response criteria for solid tumor is provided in Table 1. In 1999, the European Organization for Research and Treatment of Cancer (EORTC) first introduced metabolic information from ${ }^{18} \mathrm{~F}$ FDG-PET imaging (namely, $\mathrm{SUV}_{\max }$ ) into the response assessment criteria of oncological diseases [46]. In practice, the EORTC criteria remained in the background of RECIST until 2009 because of the well-known inherent inter-center variability of the $\mathrm{SUV}_{\max }$ PET metric [47]. In 2009, a very large step was made with the introduction of the PET-Response Criteria in Solid Tumors (PERCIST) [48]. For the first time, a critical effort has been made to propose a well-defined, reliable and robust standardized PET methodology in this field (Figure 4). To overcome the limitations of $\mathrm{SUV}_{\max }, \mathrm{SUV}_{\text {peak }}$ was introduced, together with SUV normalization by lean body mass (SUL) and a precise explanation of the definition and number of measurable targeted tumor lesions. Additionally, the percent change in $\mathrm{SUL}_{\text {peak }}$ between the two examinations was set to $30 \%$ to integrate the inter-center variabilities. The PERCIST criteria take full interest, particularly in the assessment of cytostatic chemotherapies, as they can demonstrate metabolic changes when no anatomical changes are observed. To date, PERCIST has surpassed RECIST in numerous cancer diseases for the prediction of patient outcome or the assessment of responses to treatment in many cancer diseases, emphasizing the relevance of this powerful PET-based evaluation tool. In particular, breast cancer [49], esophageal cancer [50], Ewing sarcoma [51] and non-small-cell lung cancer (NSCLC) [52,53] have been investigated for this purpose. With the emergence of immunotherapy, standard imaging criteria (both morphological and metabolic-based) have rapidly required refinements to integrate atypical response patterns such as pseudoprogression or hyperprogression diseases, which can lead to significant misclassification of patients [54]. To mirror the morphological definition of two new categories of response assessment to treatment in the dedicated iRECIST update (namely, unconfirmed and confirmed progression diseases), iPERCIST criteria were recently proposed and tested retrospectively in a study of 28 cases of NSCLC being treated with nivolumab [55]. Previously, PET/CT Criteria for Early Prediction of Response to Immune Checkpoint Inhibitor Therapy (PECRIT) have been assessed prospectively in advanced melanoma under immune checkpoint inhibitors [56]. Combining anatomical and functional imaging data to predict eventual response to ICI reached $100 \%$ sensitivity, $93 \%$ specificity and $95 \%$ accuracy. However, these findings are 
mainly limited by the small number of patients evaluated and require validation in larger cohorts. More recently, Anwar H. and coworkers proposed the PET Response Evaluation Criteria for Immunotherapy (PERCIMT) in 41 melanoma patients [57,58]. Interestingly, PERCIMT criteria consider the number of new lesions and their extent during therapy, which allows better patient stratification compared to standard SUV-based parameters. The new appearance of $\geq 4$ metabolically active lesions with functional diameters $<1.0 \mathrm{~cm}$ or $\geq 3$ lesions $>1.0 \mathrm{~cm}$ in diameter seemed correlated with real progression rather than pseudoprogression. At the same time, ${ }^{18}$ F-FDG PET imaging offers a unique opportunity to detect immune-related side effects at the whole-body level, such as thyroiditis, gastritis, colitis, pneumonitis, sarcoidosis [59] and polymyalgia rheumatica-like syndromes [60]. Interestingly, few studies have reported an association between immune activation [61] or immune-related side effects assessed by PET and patient response [62,63]. Although these recent results must be confirmed in larger prospective studies, metabolic-based imaging appears to be a promising tool in this field.

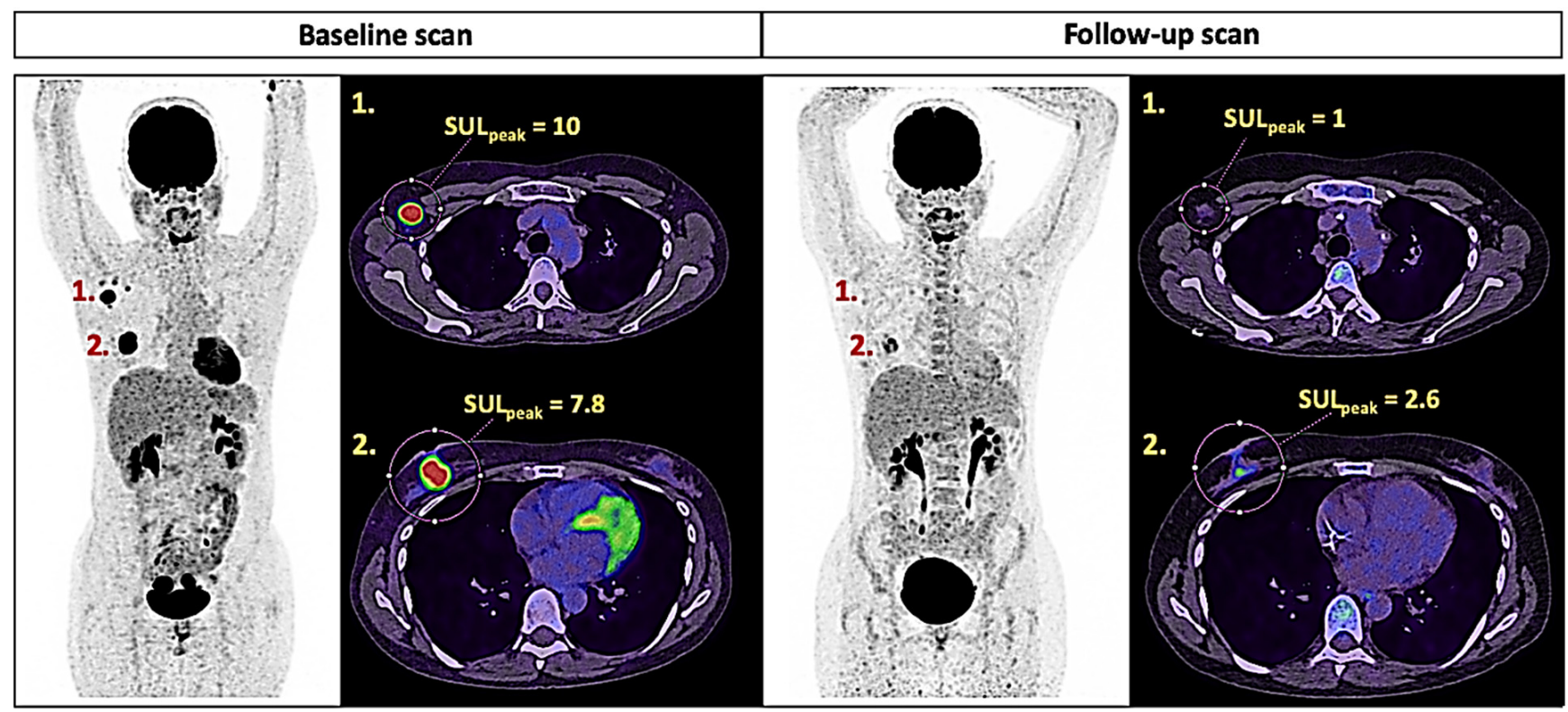

Figure 4. PERCIST tumor response assessment (breast cancer with $\mathrm{N}+$ extension, ${ }^{18} \mathrm{~F}-\mathrm{FDG}$ PET). The SUL $\mathrm{Seak}_{\text {of }}$ the targets at baseline and follow-up, measured semiautomatically from the VOI on static PET images, provided between-scan differences of $\Delta \mathrm{SUL}_{\text {peak }}=-90 \%$ and $-67 \%$, respectively, for lesions 1 and 2 . According to PERCIST criteria, it is considered a partial metabolic response $\left(\Delta \mathrm{SUL}_{\text {peak }}>-30 \%\right)$.

Table 1. Response evaluation criteria in solid tumors.

\begin{tabular}{ccccc}
\hline & & \multicolumn{2}{c}{ Response to Treatment } \\
\hline Criteria & CR & PR & SD & PD \\
\hline EORTC (1999) & $\begin{array}{c}\text { Reduction of } \\
\text { 18 F-FDG uptake } \\
\text { to background }\end{array}$ & $\begin{array}{c}\geq 15 \% \text { reduction } \\
\text { of }{ }^{18} \text { F-FDG uptake }\end{array}$ & $\begin{array}{c}\text { Neither } \\
\text { CR, PR nor PD }\end{array}$ & $\begin{array}{c}\geq 25 \% \text { increase in } \\
18 \text { F-FDG uptake }\end{array}$ \\
\hline PERCIST (2009) & $\begin{array}{c}\text { Reduction of } \\
\text { 18F-FDG uptake } \\
\text { to background }\end{array}$ & $\begin{array}{c}\geq 30 \% \text { reduction } \\
\text { in SULpeak }\end{array}$ & $\begin{array}{c}\text { Neither } \\
\text { CR, PR nor PD }\end{array}$ & $>30 \%$ increase in SUL peak \\
\hline
\end{tabular}


Table 1. Cont.

\begin{tabular}{|c|c|c|c|c|}
\hline \multirow[b]{2}{*}{ Criteria } & \multicolumn{4}{|c|}{ Response to Treatment } \\
\hline & CR & PR & SD & PD \\
\hline PECRIT (2017) & $\begin{array}{l}\text { Metabolic } \\
\text { disappearance of target; } \\
\text { SAD reduction of LN }\end{array}$ & $\begin{array}{l}\geq 30 \% \text { reduction in } \\
\text { SULpeak } \\
\geq 30 \% \text { decrease in } \mathrm{TL} \\
\text { diameter sum }\end{array}$ & $\begin{array}{c}\text { Neither } \\
\text { CR, PR nor PD }\end{array}$ & $\begin{array}{c}>30 \% \text { increase in SUL peak } \\
\text { Or new metabolically } \\
\text { active lesion } \\
\geq 20 \% \text { increase in TL diameter } \\
\text { Or new lesions }\end{array}$ \\
\hline PERCIMT (2018) & $\begin{array}{l}\text { Complete resolution of } \\
\text { all } \\
{ }^{18} \text { F-FDG-avid lesions }\end{array}$ & $\begin{array}{l}\text { Complete resolution of } \\
\text { some }{ }^{18} \text { F-FDG- lesions }\end{array}$ & $\begin{array}{c}\text { Neither } \\
\text { CR, PR nor PD }\end{array}$ & $\begin{array}{c}\geq 4 \text { new lesions } \leq 10 \mathrm{~mm} \\
\text { Or } \geq 3 \text { new lesions }>10 \mathrm{~mm} \\
\text { Or } \geq 2 \text { new lesions }>15 \mathrm{~mm}\end{array}$ \\
\hline iPERCIST (2019) & $\begin{array}{l}\text { Complete resolution of } \\
{ }^{18} \text { F-FDG uptake }\end{array}$ & $\begin{array}{l}\geq 30 \% \text { decrease in the } \\
\text { target tumor }{ }^{18} \text { F-FDG }\end{array}$ & $\begin{array}{c}\text { Neither } \\
\text { CR, PR nor PD }\end{array}$ & $\begin{array}{c}\quad \geq 30 \%{ }^{18} \text { F-FDG uptake } \\
\text { Or } \\
\text { new }{ }^{18} \text { F-FDG target (UPMD). } \\
\text { Need second PET at } 4-8 \text { weeks } \\
\text { later (CPMD); if progression is } \\
\text { followed by PMR or SMD, the } \\
\text { bar is reset. }\end{array}$ \\
\hline
\end{tabular}

CR: Complete response, CT: Computed Tomography, ${ }^{18}$ F-FDG: ${ }^{18}$ F-Fluorodeoxyglucose, PD: Progressive Disease, PET: Positron emission tomography, PR: Partial response, SAD: Short-Axis Diameter, SUL: SUV normalized by lean body mass, TL: Target Lesions, UPMD: Unconfirmed Progressive Metabolic Disease, CPMD: Confirmed Progressive Metabolic Disease, PMR: Partial Metabolic Response, SMD: Stable Metabolic Disease.

\subsection{Lymphoma}

In Hodgkin Lymphoma (HL) and Non-Hodgkin Lymphoma (NHL, mainly Diffuse large B-cell lymphoma DLBCL), given the natural high avidity of aggressive tumor cells for ${ }^{18} \mathrm{~F}-\mathrm{FDG}$ and the binary metabolic response to treatment, dedicated PET response evaluation criteria have progressively emerged to currently become the most powerful imaging tool in this field (Table 2). Considering the extensive evidence-based literature of the first decade of the 21st century, PET was integrated into the international guidelines for response assessment of lymphoma in 2007 [64], a revised version of the historical international working group morphological criteria [65]. Seven years later, the Lugano criteria refined these guidelines [66], confirming the role of PET as a key imaging modality in the diagnosis and response assessment of lymphoma. PET imaging was definitively integrated into the Ann Arbor staging system (Lugano staging classification), and the PET Deauville 5-point visual grading scale was defined as the main response evaluation tool (in standard therapeutic schemes, end-treatment scores of 1, 2 or 3 were considered $\mathrm{CR}$, whereas scores of 4 and 5 were considered non-responses, as illustrated in Figure 5). Additionally, based on the relevance of PET in this field, bone marrow biopsy is no longer indicated for the assessment of bone marrow involvement in HL and is only required in negative PET cases with consequences for patient management in DLBCL. To increase the reliability of the procedure and improve the prognostic value of PET imaging, interim SUV-based semiquantitative metrics are currently being extensively investigated $[28,67,68]$. In particular, a very recent large prospective study with 158 new DLBCL patients reported higher prognostic value for interim SUV-based metrics (interim $\triangle \mathrm{SUV}_{\max }=$ percent change between baseline PET and PET performed after two cycles of treatment) compared to the standard visual grading scale evaluation [69]. In particular, only the interim $\Delta \mathrm{SUV}_{\max }$ predicted both PFS and OS. These findings and those of other recent clinical trials highlight the relevance of using more quantitative PET methods in this field [70,71]. Finally, for solid tumors, PET imaging criteria were recently adapted to immunotherapy by integrating indeterminate response features: the lymphoma response to immunomodulatory therapy criteria (LYRIC) in 2016 [72] and the Response Evaluation Criteria in Lymphoma (RECIL) in 2017, with more morphological parameter weighting [73]. 
Table 2. Response evaluation criteria in lymphoma.

\begin{tabular}{|c|c|c|c|c|}
\hline & \multicolumn{4}{|c|}{ Response to Treatment } \\
\hline Criteria & CR & PR & SD & PD \\
\hline $\begin{array}{l}\text { LUGANO } \\
\text { (2014) }\end{array}$ & $\begin{array}{ll}\text { - } & \text { CT: reduction of lesions } \\
\text { - } & \text { PE normal size } \\
\text { PET: normalized } \\
{ }^{18} \text { F-FDG-uptake (DS 1-3) }\end{array}$ & $\begin{array}{l}\text { CT: } \geq 50 \% \\
\text { reduction in SPD } \\
\text { of up to 6 lesions } \\
\text { PET: reduced } \\
\text { 18F-FDG-uptake } \\
\text { (DS 4-5) }\end{array}$ & $\begin{array}{l}\text { - CT: neither } \\
\text { sufficient change } \\
\text { for PD nor PR } \\
\text { PET: unchanged } \\
\text { 18F-FDG-uptake } \\
\text { (DS 4-5) }\end{array}$ & $\begin{array}{ll}- & \mathrm{CT}: \geq 50 \% \text { increase in SPD of lesions } \\
\text { - } & \text { New lesion(s) } \\
& \text { PET: increased 18F-FDG-uptake } \\
& \text { (DS 4-5) or new 18F-FDG-avid lesions }\end{array}$ \\
\hline $\begin{array}{l}\text { LYRIC } \\
\text { (2016) }\end{array}$ & - Same as Lugano & - $\quad$ Same as Lugano & - Same as Lugano & $\begin{array}{l}\text { Adapted from Lugano to indeterminate } \\
\text { response (IR) categories: } \\
\text { - IR1: } \geq 50 \% \text { increase in SPD in } \\
\text { 12 weeks without clinical } \\
\text { deterioration } \\
\text { IR2: }<50 \% \text { increase in SPD with new } \\
\text { lesion(s), or } \geq 50 \% \text { increase in SPD of } \\
\text { a lesion or set of lesions at any time } \\
\text { during treatment } \\
\text { IR3: increase in } 18 \text { F-FDG-uptake } \\
\text { without increase in lesion size } \\
\text { meeting criteria for PD }\end{array}$ \\
\hline $\begin{array}{l}\text { RECIL } \\
(2017)\end{array}$ & $\begin{array}{l}\text { CT: complete } \\
\text { disappearance of all TL } \\
\text { and all nodes with LD } \\
\text { <10 mm } \\
\text { PET: normalized } \\
\text { 18F-FDG-uptake } \\
\text { (DS 1-3) }\end{array}$ & 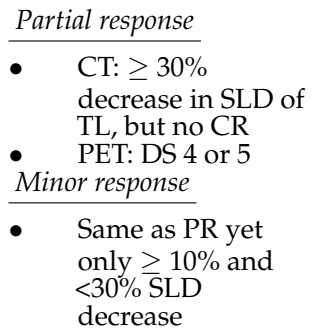 & $\begin{array}{l}\text { CT: }<10 \% \text { decrease } \\
\text { or } \leq 20 \% \text { increase } \\
\text { SLD of TL } \\
\text { PET: any DS }\end{array}$ & $\begin{array}{l}\text { - } \quad \text { CT: }>20 \% \text { increase in SLD of TL } \\
\text { - For small lymph nodes }<15 \mathrm{~mm} \text { after } \\
\text { therapy, a minimum absolute } \\
\text { increase of } 5 \mathrm{~mm} \text { and the } \mathrm{LD}>15 \mathrm{~mm} \\
\text { - New lesion(s) } \\
\text { PET: any DS }\end{array}$ \\
\hline
\end{tabular}

CT: Computed Tomography, DS: Deauville score, ${ }^{18}$ F-FDG: Fluorodeoxyglucose, IR: Indeterminate Response, LD: Long diameter, PD: Progressive Disease, PET: Positron Emission Tomography, PR: Partial Response, SLD: Sum of Longest Diameters, SPD: Sum of Perpendicular Diameters, TL: Target Lesions.

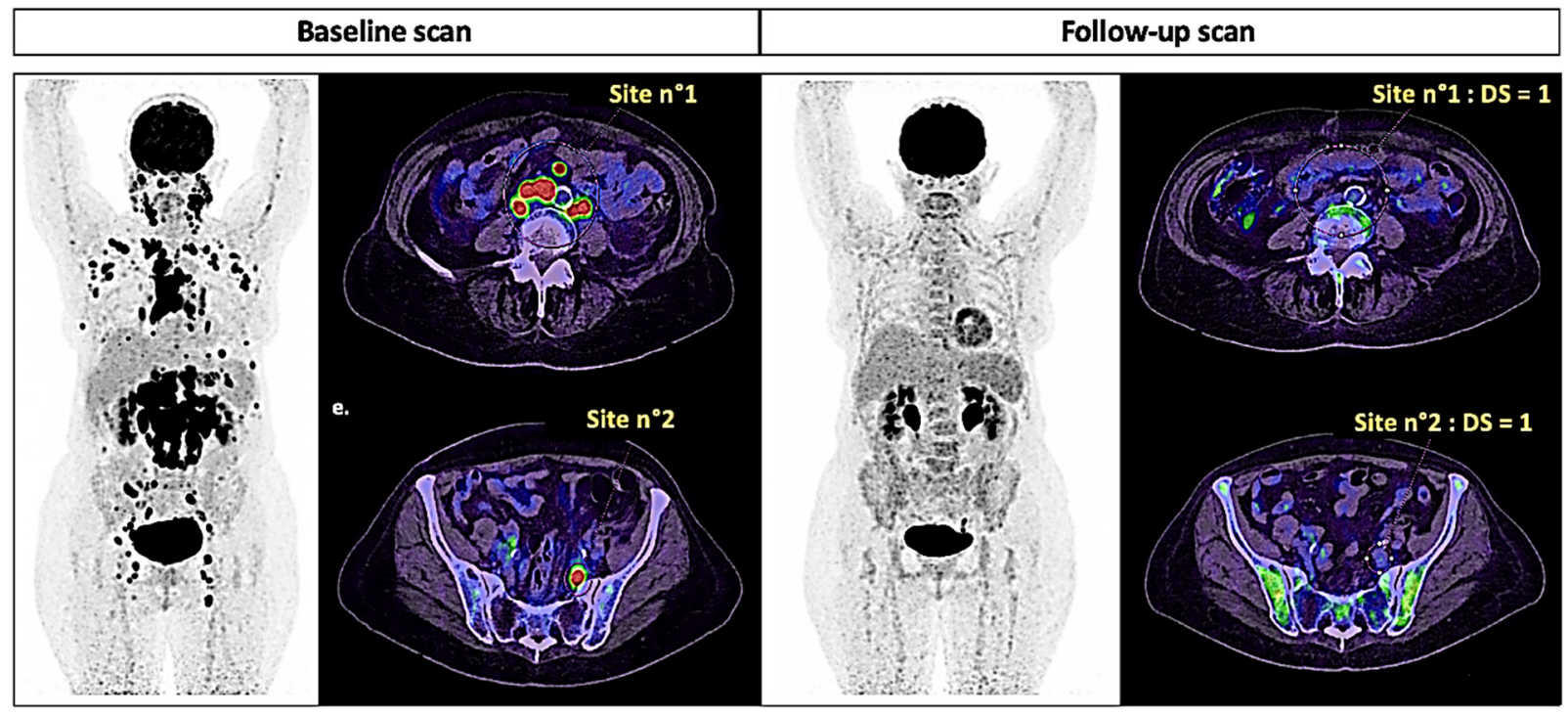

Figure 5. Lugano response assessment for lymphoma (DLBCL stage IV Ann Arbor, ${ }^{18}$ F-FDG PET). Visual grading assessment at follow-up corresponds to a Deauville score of 1 ( $D S=1$, no visual uptake). According to the Lugano criteria, it is considered a complete metabolic response.

\subsection{Multiple Myeloma}

Magnetic resonance imaging (MRI) is considered the gold standard to detect bone marrow involvement in multiple myeloma due to its very high anatomical resolution and soft tissue contrast. However, its limited value in assessing the response to treatment and 
the time-consuming whole-body acquisition protocols have promoted the use of ${ }^{18}$ F-FDG $\mathrm{PET} / \mathrm{CT}$ as a fast-whole-body complement imaging modality to manage patients with MGUS and multiple myeloma. In comparison with MRI, ${ }^{18}$ F-FDG PET/CT shows faster normalization of image findings [74]. Recently, the International Myeloma Working Group has integrated ${ }^{18}$ F-FDG PET/CT into the diagnostic criteria of multiple myeloma, considering abnormal bone ${ }^{18} \mathrm{~F}-\mathrm{FDG}$ uptake as a C.R.A.B feature $(\mathrm{C}=$ hypercalcemia; $\mathrm{R}=$ renal failure; $\mathrm{A}=$ anemia; and $\mathrm{B}=$ bone lesions) [75]. Although clinically promising in this field, several drawbacks make the interpretation of ${ }^{18} \mathrm{~F}$-FDG PET challenging in multiple myeloma, especially at the time of initial diagnosis: as a heterogeneous disease, multiple myeloma can present with variable metabolic uptake, ranging from low to extremely high; additionally, anemia and G-CSF may stimulate BM uptake, reducing the detectability of axial targets. All these challenging aspects and pitfalls require extensive experience and knowledge of the particular aspects of MM. In past years, different interpretation criteria have been proposed. Some groups have proposed semiquantitative SUV-based parameters to assess the disease burden [76]. Recently, a consortium of nuclear medicine experts, hematologists and medical physicists proposed standardized criteria to promote the use of PET in clinical trials: the Italian myeloma criteria for PET use (IMPeTUs). These new criteria, combining the Deauville five-point scale and morphological features (site and number of lytic lesions, Table 3) [77], have provided high reproducibility and can be considered a basis for harmonizing PET interpretation in multiple myeloma. Although recent findings showed the prognostic value of these criteria for both OS and DFS [20], further prospective clinical trials are warranted to confirm the relevance of IMPETUS in this field.

Table 3. Response evaluation criteria in multiple myeloma.

\begin{tabular}{|c|c|c|c|}
\hline Lesion Type & Site & Number of Lesions ( $x$ ) & Grading \\
\hline Diffuse & Bone marrow & & Deauville scale (five points) \\
\hline 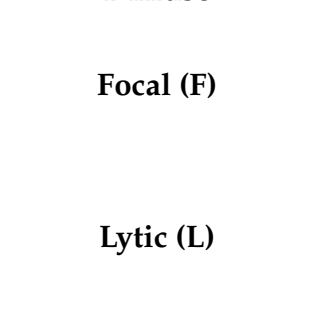 & $\begin{array}{c}\text { Skull (S) } \\
\text { Spine (SP) } \\
\text { Extraspinal (ExP) }\end{array}$ & $\begin{array}{c}x=1 \text { (no lesions) } \\
x=2(1 \text { to } 3 \text { lesions }) \\
x=3(4 \text { to } 10 \text { lesions }) \\
x=4(>10 \text { lesions }) \\
x=1 \text { (no lesions }) \\
x=2(1 \text { to } 3 \text { lesions }) \\
x=3(4 \text { to } 10 \text { lesions }) \\
x=4(>10 \text { lesions })\end{array}$ & Deauville scale (five points) \\
\hline $\begin{array}{c}\text { Fracture (Fr) } \\
\text { Paramedullary (PM) }\end{array}$ & $\begin{array}{l}\text { At least one } \\
\text { At least one }\end{array}$ & & \\
\hline Extramedullary (EM) & At least one & $\begin{array}{c}\text { N/EN } \\
(\text { Nodal/ExtraNodal }) *\end{array}$ & Deauville scale (five points) \\
\hline
\end{tabular}

${ }^{*}$ For nodal disease (N): C: Cervical, SC: Supraclavicular, M: Mediastinal, Ax: Axillary, Rp: Retroperitoneal, Oth: Other, Mes: Mesenteric, In: Inguinal. For extranodal disease (EN): Li: Liver, Mus: Muscle, Spl: Spleen, Sk: Skin.

\section{PET Molecular Imaging: The Promising Clinical Perspective of Radioligand Molecular Imaging and Therapy}

PET imaging detection is conceptually based on the radionuclide labeling of molecular probes. Considering several intrinsic chemical limitations of vector-radioligand coupling, PET molecular imaging provides almost unlimited opportunities to map numerous physiological or pathophysiological targeted processes at the whole-body level, with picomolar detection sensitivity (Figure 6). In the last decade, the integration of PET imaging with radionuclide therapy, also known as radiolabeled theranostics, has paved the way towards highly sensitive radionuclide-based precision medicine. In particular, major breakthroughs are currently expected in two clinical fields: neuroendocrine tumors (NETs) and prostate cancer (PCa). 


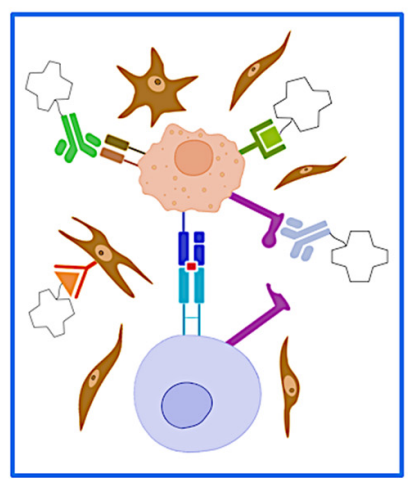

$\underline{\text { Vectors }}$

CAFs

Glucose metabolism

Hypoxia

Membrane renewing

Oestrogen

PD1/PD-L1

PSMA

Somatostatin

...

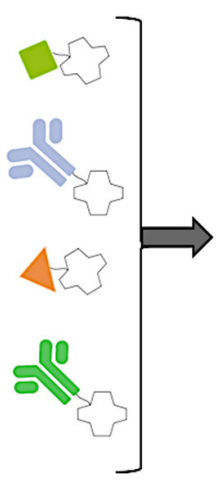

Vector radiolabeling

(2)

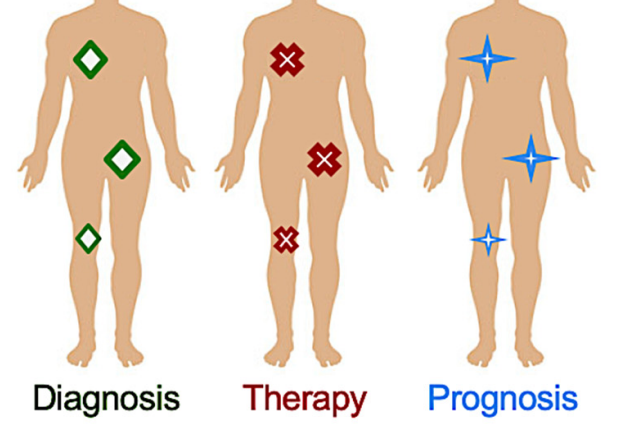

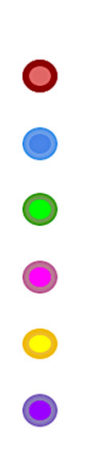

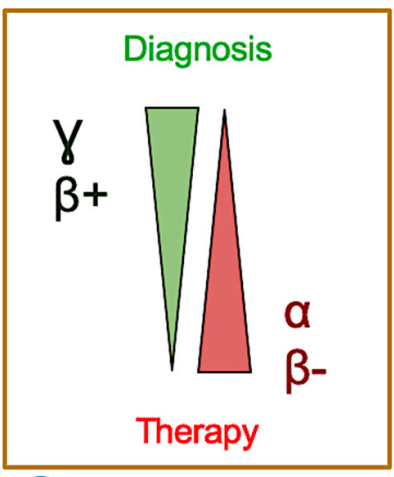

Radionuclides

${ }^{225} \mathrm{Ac}$

${ }^{11} \mathrm{C}$

$18 \mathrm{~F}$

${ }^{68} \mathrm{Ga}$

${ }^{177} \mathrm{Lu}$

90Y

$89 \mathrm{Zr}$

Figure 6. Principles of vectorized PET molecular imaging. Numerous relevant molecular probes constitute a powerful arsenal to characterize tumor biological processes in vivo. Vector radiolabeling by diagnostic radionuclides, in particular PET radionuclides ( $\beta^{+}$emitters), allows tumor molecular targeted mapping (quantification at the whole-body level for diagnosis/prognosis and monitoring purposes). For the same vector, switching from diagnostic to therapeutic radiolabeling (either $\alpha$ or $\beta^{-}$), so-called theranostics, allows vectorized internal radiation therapy with precise characterization of the tumor burden biodistribution. Therapeutic radionuclides have their own properties. With their very short radiation range of $47-85 \mu \mathrm{m}$, high energy $\alpha$-emitters $\left({ }^{225} \mathrm{Ac}\right)$ provide limited off-targeted irradiations with a high local cytotoxic effect, regardless of the cycle phase or oxygenation status. Importantly, these emitters require a high degree of target internalization. Currently, their use is limited by the worldwide production capabilities. Of lower energy and better available in practice, $\beta^{-}$emitters $\left({ }^{177} \mathrm{Lu},{ }^{90} \mathrm{Y}\right)$ provide better penetration ranges (several $\mathrm{mm}$ ), which is of particular interest in the case of high targeted or heterogenous volumes, but induces higher hematological and renal toxicities.

\subsection{NETS}

According to the Surveillance Research Program of the National Cancer Institute [78], NETs account for only $0.49 \%$ of all malignancies. However, an unexplained increased incidence has been observed over the past decades. The emergence of somatostatin receptorbased PET diagnostic imaging revolutionized patient care in the late 1980s, for whom strategy management was very limited $[79,80]$. A further step was reached with the emergence of PET-based somatostatin receptor-imaging in the 2000s, combining the inherent higher physical properties of PET systems over conventional scintigraphy (spatial resolution, sensitivity detection, unbiased quantification), improved kinetics (faster clearance and tissue penetration with the last generations of targeted radioligands) and chemical properties (chelation-based, allowing fast and rapid vectorized radioligand switching from diagnosis with ${ }^{68} \mathrm{Ga}$ to therapy with ${ }^{90} \mathrm{Y},{ }^{177} \mathrm{Lu}$ or ${ }^{225} \mathrm{Ac}$ ) [81-83]. Based on 2105 patients, the pooled diagnostic performance of SSR-PET from 22 studies provided a sensitivity and specificity of $93 \%$ (95\% CI 91-94\%) and 96\% (95\% CI 95-98\%), respectively [84], surpassing conventional scintigraphy in this field [85]. Such detection performance led to the integration of SSR-PET into the international strategy of patient management, from initial staging to recurrence and palliative care for almost all NETs [86,87] (Figure 7). Recently, the phase III NeuroEndocrine Tumors Therapy clinical trial (NETTER-1) validated the use of SSR-based radioligand therapy in well-differentiated metastatic NETs of the 
midgut [88]: ${ }^{177} \mathrm{Lu}-\mathrm{SSR}$ showed a 79\% reduction in risk of progression and an estimated PFS of 40 months compared to 8.4 months for high-dose octreotide therapy (79\% lower risk of disease progression or death in the 177Lu-Dotatate group). For undifferentiated high-grade NETs, SSR-based radioligand therapy is still debated [89,90]. Some findings suggest that aggressive and higher grade 2-3 NETs but still well-differentiated with sufficient expression of somatostatin receptor to be visualized through prognostic SSR-PET could benefit from SSR-based radioligand therapy [91]. The ongoing NETTER-2 clinical trial (registered as NCT03972488) should answer this question. Finally, beyond SSR-PET, standard FDG PET may be used as a complementary tumor burden mapping in the patient management strategy due to its powerful independent prognostic value [92,93].

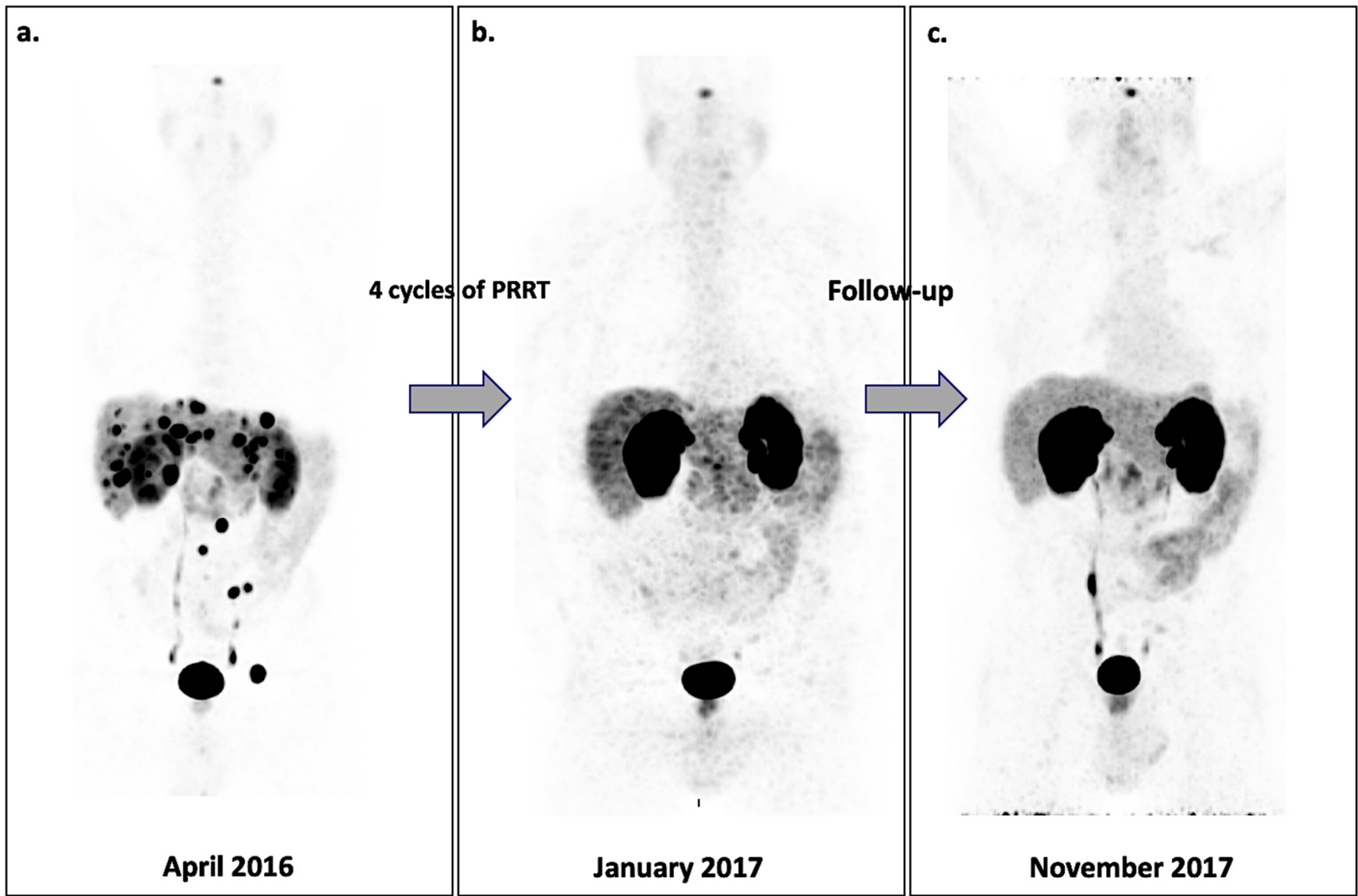

Figure 7. Theranostics and Peptide Receptor Radionuclide Therapy (PRRT). A patient with a NET diagnosed in 2015 (T3N0M1, G2, 20\% Ki67) who was treated by surgery (distal pancreatectomy, splenectomy and liver resection) and radiofrequency ablation (liver metastasis). Somatostatin receptor (SSTR) PET imaging performed with ${ }^{68}$ Ga-DOTATOC before PRRT in April 2016 was positive, showing disseminated liver and bone lesions with intense uptake (Krenning score $=4)(\mathbf{a})$. After ${ }^{177} \mathrm{Lu}$-octreotide, all the foci disappeared (Krenning score $\left.=0\right)$ on posttreatment $(\mathbf{b})$ and follow-up ${ }^{68} \mathrm{Ga}-$ DOTATOC PET (c), illustrating a complete response. Images courtesy of Jérémie Calais and Martin Auerbach (Ahmanson Translational Theranostics Division, UCLA, Los Angeles, CA, USA).

\section{2. $\mathrm{PCa}$}

Prostate cancer is the second most frequent malignancy in men worldwide [94]. Because of the limited value of standard imaging, choline PET (a membrane phospholipid radiolabeled either with ${ }^{11} \mathrm{C}$ or ${ }^{18} \mathrm{~F}$ ) was widely used in the 2000s for the early assessment of biochemically recurrent prostate cancer. Extensive literature has shown choline PET to be of high relevance for the detection of recurrent lymph nodes or bone metastases in treated patients, especially with PSA above $2 \mathrm{ng} / \mathrm{mL}$ or high PSA velocity/doubling 
time [95-97]. However, poorer detection rates for PSA under $2 \mathrm{ng} / \mathrm{mL}$ and low specificity for treatment-naïve patients motivated the development of more specific molecular probes in this field. In this context, prostate-specific membrane antigen (PSMA), a transmembrane protein of unclear biological function that is overexpressed 100- to 10,000-fold in PCa cells compared to normal tissues [98-100], has gained increasing interest in the last decade. Given its high sensitivity for the detection of PCa lesions, PSMA radiolabeling is currently changing the methods for managing early biochemically recurrent $\mathrm{PCa}$ and occult metastatic PCa, for which conventional imaging modalities (MRI and CT) lack sensitivity and specificity [101]. Except for neuroendocrine PCa [102], PSMA expression increases with tumor dedifferentiation and in metastatic castration-resistant prostate cancer. A recent pooled analysis of 5113 patients ( 43 studies) imaged with ${ }^{68} \mathrm{Ga}$ PSMA PET showed overall detection rates of $94 \%$ at PSA levels above $2.0 \mathrm{ng} / \mathrm{mL}$ for biochemically recurrent PCa treated by radical prostatectomy, with higher detection rates than conventional imaging at PSA levels under $0.5 \mathrm{ng} / \mathrm{mL}$ [103]. Moreover, numerous studies have shown that PSMA PET radiotracers surpasses the actual concurrence (choline or fluciclovine PET radiotracers) to detect biochemically recurrent PCa, especially at PSA levels under $1 \mathrm{ng} / \mathrm{mL}$ (for reviews, please refer to $[104,105])$. Beyond recurrent disease management and given the growing literature in this field, especially the very good agreement with histology [106,107], PSMA PET has been rapidly imposed for the primary management of PCa patients [108-110]. In December 2020, the US Food and Drug administration granted the first clinical approval for institutional use (University of California, UCLA and USCF) of ${ }^{68} \mathrm{Ga}$ PSMA PET (PSMA-11) for the initial staging and the detection of recurrence in PCa patients based on recent clinical trial findings [111-114]. This milestone achievement should pave the way to a new standard of care for patients with PCa. From this perspective, and for simpler availability and production workflows, several diagnostic ${ }^{18} \mathrm{~F}$-radiolabeled PSMA PET tracers have already been integrated into the research pipeline [115-118]. Together with these recent imaging advances, PSMA radioligand therapy has also emerged in patients with metastatic castration-resistant PCa (Figure 8). Mainly based on small-molecule inhibitors of PSMA (PSMA-I\&T, PSMA-617), 10 large phase I-III PSMA RLT trials are currently ongoing and are using either ${ }^{177} \mathrm{Lu}$ or ${ }^{225} \mathrm{Ac}$ radionuclides (for details please refer to [119]). Among the promising literature findings already published, two prospective clinical trials are considered a very large step in this field: the LuPSMA trial, a single-arm phase 2 study that assessed the safety and efficacy of ${ }^{177}$ Lu-PSMA-617 in 30 patients with metastatic castrationresistant PCa [120], and the TheraP multicenter randomized open-label phase 2 trial, which showed a decrease in PSA levels of at least $50 \%$ from baseline for the ${ }^{177} \mathrm{Lu}-\mathrm{PSMA}-617$ group compared to the cabazitaxel group, along with longer PFS (HR 0.63, $p=0.0028$ ), lower toxicity events and higher pain improvement [121]. Finally, the very recent first historical standardized reporting guideline for PET imaging in this field emphasizes the growing importance of PSMA-based radiotracers in the management of PCa and the strong motivation of the international nuclear imaging community to accelerate its use in future clinical trials [122]. 
a.

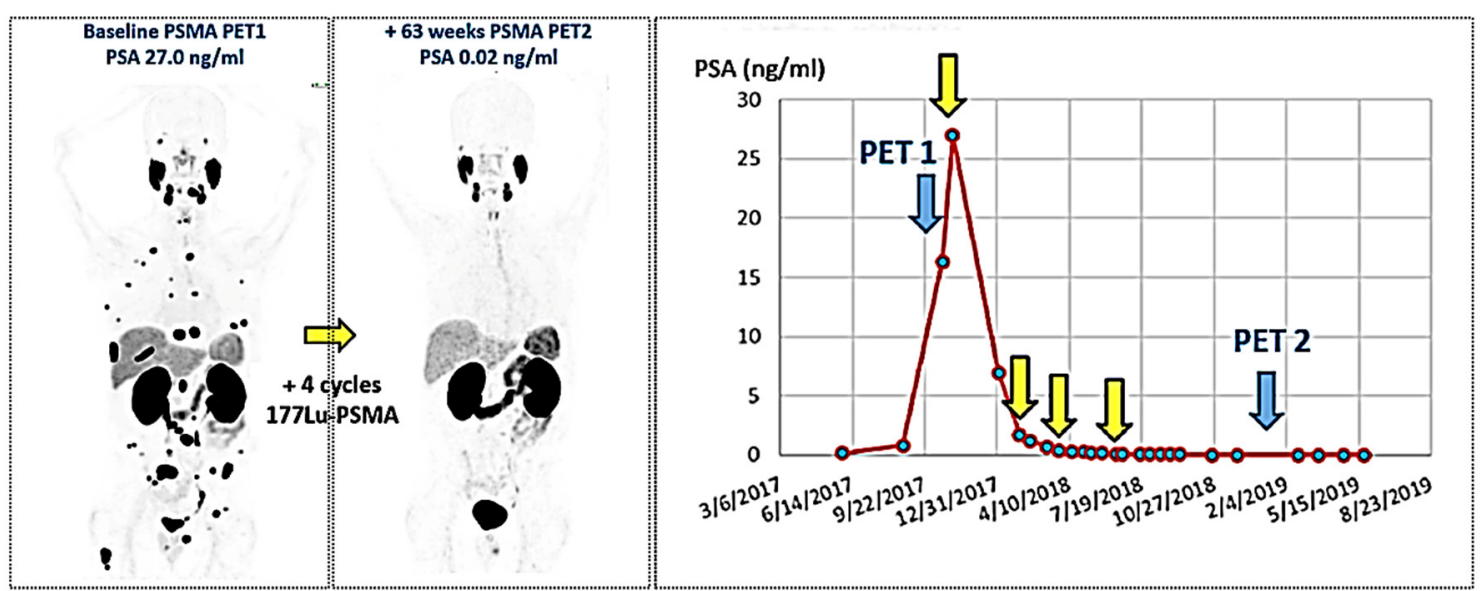

b.

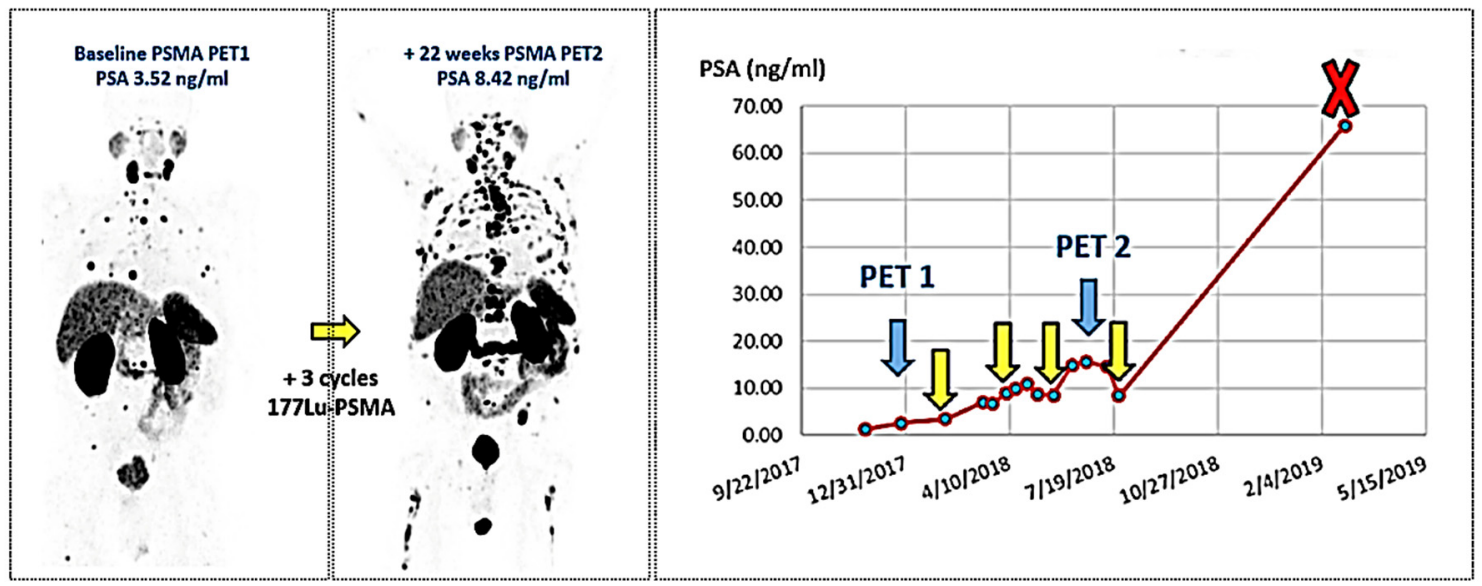

Figure 8. Theranostics and PSMA radionuclide therapy. (a) Example of a patient with PCa with complete response after treatment with ${ }^{177} \mathrm{Lu}-\mathrm{PSMA}-617$ : all the lesions disappeared on the follow-up ${ }^{68}$ Ga-PSMA PET at one year, together with the PSA level. (b) Despite the impressive successes reported with ${ }^{177} \mathrm{Lu}-\mathrm{PSMA}$, several problems remain unresolved, as illustrated in this nonresponder case, with significant progression on the follow-up ${ }^{68} \mathrm{Ga}$-PSMA PET, together with the rising curve of PSA after treatment. Images courtesy of Jérémie Calais (Ahmanson Translational Theranostics Division, UCLA, Los Angeles, CA, USA).

\subsection{Other Near-Future Promising Perspectives in Clinical Practice: Immuno-PET and Beyond}

Beyond the emerging success of NETs and PCa radioligand targeting, various molecular cancer targets have been developed since the historical use of ${ }^{18}$ F-FDG in the late 1980s [123], based on the fundamental aerobic glycolytic properties of cancer cells, also known as the "Warburg effect" [124]. Emphasizing the unique capability of PET molecular imaging to constantly adapt to emerging oncological challenges, other biological properties of cancer have been assessed in numerous phase 0-3 trials, including hypoxia, apoptosis or protein synthesis (for review please refer to [125]). The hallmark capabilities of cancer are an evolving concept [126], and tumor immunity (tumor cells and the interlinks with their immune microenvironment) is currently a very hot topic of interest, given the revolution provided by immunotherapy checkpoint inhibitors [127,128]. Despite progressing results since the first FDA approval in 2011, the response rate to checkpoint inhibitors remains approximately 13\% of eligible patients [129]. Many efforts are currently made to better identify patients who would be eligible for these new drugs $[130,131]$. Additionally, the numerous updates of limited current imaging criteria illustrate the needs of new tools to better characterize the immune ecosystem of tumors to improve treatment strategies [132,133]. Immune checkpoint-targeted radiolabeled monoclonal antibodies (IC-PET) and fibroblast activation protein-targeted radiolabeled inhibitors (FAPi-PET) are 
two serious candidates in this field. In the last five years, several dozen preclinical IC-PET studies with ${ }^{64} \mathrm{Cu},{ }^{89} \mathrm{Zr},{ }^{68} \mathrm{Ga},{ }^{124} \mathrm{I}$ or ${ }^{18} \mathrm{~F}$ radionuclides have been published, but numerous challenging technical considerations remain to reach optimal IC-PET pharmacokinetics and biodistribution in practice (size, Fc-mediated functions and charge, radiolabeling strategy) (Figure 9); for a review, please refer to [134]. Two very recent first-in-human studies assessed its clinical safety and feasibility $[135,136]$. The results from the study by Niemeijer and coworkers showed that for 13 patients with advanced NSCLC (follow-up of 3 months), IC-PET ( ${ }^{89} \mathrm{Zr}$-nivolumab) findings correlated with immunohistochemistry [136]. In the study by Bensch $F$ and coworkers, who included 25 patients with various cancer subtypes (bladder, NSCLC, triple negative breast cancers; median follow-up of 21.9 months), IC-PET ( ${ }^{89} \mathrm{Zr}$-atezolizumab) better correlated with PFS and OS than immunohistochemistry or RNA-sequencing [135]. These very promising results have promoted the launch of numerous IC-PET clinical trials focusing on NSCLC, HNSCC, lymphomas, RCC, breast cancers and melanomas (for a review please refer to [134]). Finally, FAPi-PET has recently emerged as a PET molecule targeting cancer-associated fibroblasts (CAFs) [137-139]. CAFs play critical roles in tumor progression and immunity regulation and represent a promising therapeutic target [140]. Activated CAFs highly express FAP, a glycoprotein enzyme with peptidase activity [141]. Combining both PET molecular probes of tumor cells $\left({ }^{18} \mathrm{~F}-\mathrm{FDG}\right.$ PET) and their surrounding stroma (FAPi PET) provides an open exciting perspective, as illustrated by recent findings in oncological patients with inconclusive ${ }^{18}$ F-FDG PET findings [142], or to optimize the tumor volume delineation for radiotherapy planning [143]. Together with imaging capabilities, FAP-radioligand therapy is also under development [144,145], paving the way towards stroma-targeted radiolabeled theranostics.

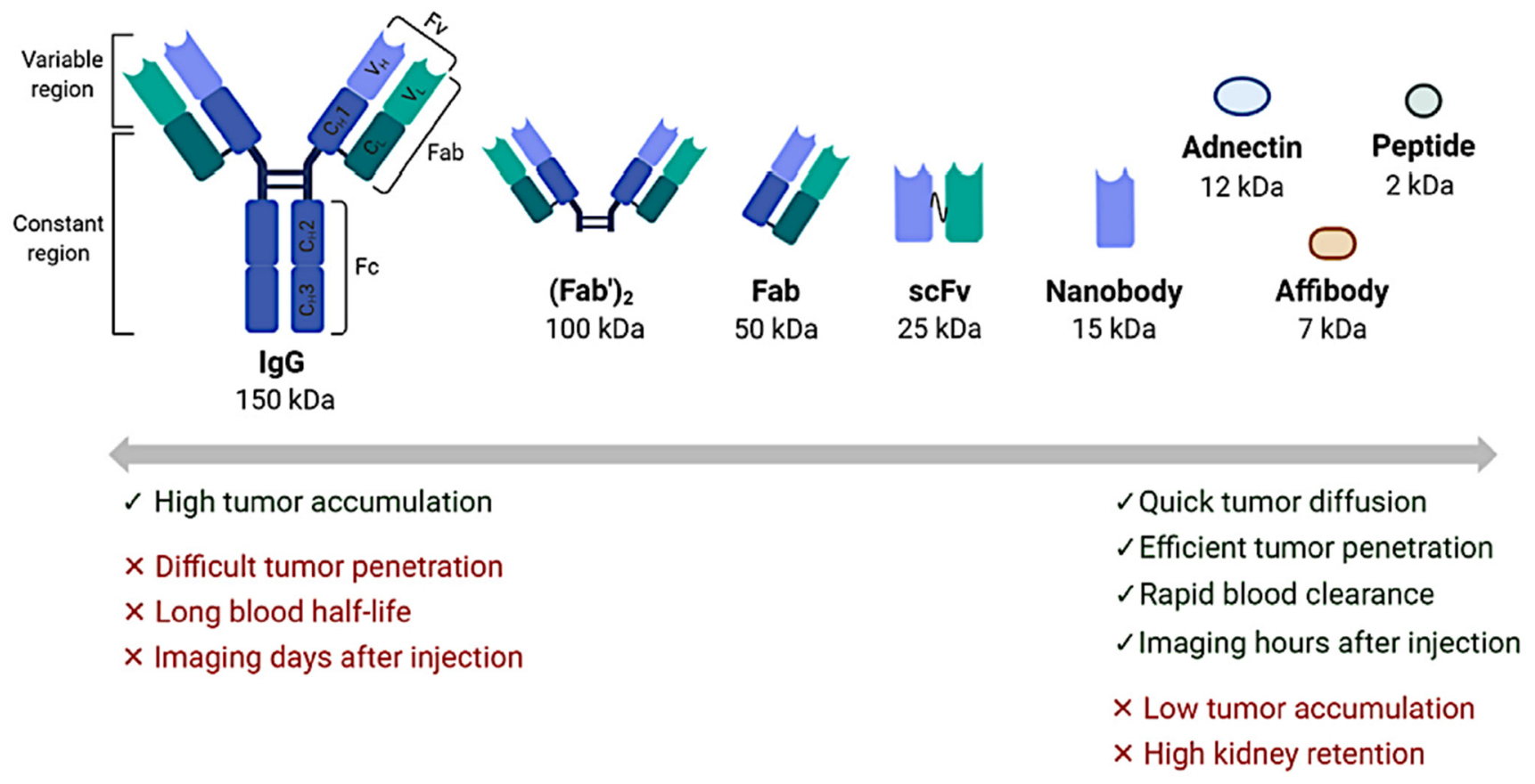

Figure 9. Different radioligand formats for in vivo PET imaging. A schematic representation of various radioligand formats with distinct pharmacokinetic properties that can be used for PET imaging of immune checkpoints: intact IgG antibody; antibody-derived fragments, including $\left(\mathrm{Fab}^{\prime}\right) 2$, Fab, scFv and nanobody; and smaller protein scaffolds (adnectin, affibody, small peptide). Abbreviations: VL: light-chain variable domain; VH: heavy-chain variable domain; CL: light-chain constant domain; $\mathrm{CH}$ : heavy-chain constant domain. Image and legend courtesy of Alizée Bouleau/Charles Truillet/Vincent Lebon (Université Paris Saclay, CEA, CNRS, Inserm, BioMaps) [134]. 


\section{PET Molecular Imaging: The Perspectives of Statistical and Computer Sciences for Multidimensional Image-Based Decision Making}

In the last 20 years, the concept of tumor heterogeneity-where a tumor mass is considered a patchwork of distinct genotypic and phenotypic subcellular populationshas been imposed as a strong factor of treatment resistance [146,147]. In this context, the unsuitability of standard image-based criteria to accurately assess the response to nonconventional therapies $[148,149]$, together with the rapid emergence of computer science in the field of medical imaging, promoted the development of radiomics-the extraction of high-throughput quantitative metrics from medical images-which is a largescale image-based approach derived from OMICS (genomics, transcriptomics, proteomics, metabolomics, etc.) of which the purpose is to better capture tumor heterogeneity from standard-of-care medical images to build relevant diagnostic or predictive models [150]. Despite promising FDG PET results in the early 2000s [151,152] and efforts in recent years to propose "user-friendly" dedicated software for clinical use, radiomics has not yet reached a sufficient level of relevance in clinical practice [153]. In essence, the standard radiomics pipeline integrates image acquisition, segmentation and standardization, handcrafted feature extraction (intensity, shape and texture parameters) and selection through machine learning-based statistical analyses to build optimized diagnosis and prognosis endpoint models. One major drawback of such a huge operational processing pipeline remains its multilevel subjectivity and technical dependencies [154]. A recent systematic review based on 624 records (41 full-text articles mixing lung, head and neck, esophageal, rectal, cervical and breast cancers, mainly describing CT and PET findings) specifically addressed the repeatability and reliability of radiomic features and reported probable high variability at each main processing step for the majority of second- (shape-based metrics) and third-order (texture-based metrics) feature classes [155]. Nonetheless, this field of research is maturing based on years of hindsight. In 2020, the Imaging Biomarkers Standardization Initiative (IBSI), a task force of 20 research groups, established international standardized frameworks for radiomics computation and validated the use of 164 PET radiomics features [156]. Another major issue concerns the use of unsuitable statistical procedures in the vast majority of reported radiomics studies, probably partly explained by two factors: the strong difficulty of collecting and structuring large homogeneous datasets in "real-life" clinical practice [157] and the lack of knowledge in machine learning/data mining, a "new" field of skills to be learned by nuclear medicine practitioners. Again, the practice is maturing. Harmonization procedures have emerged to facilitate multicenter studies in practice and remove the so-called "center effect" [158,159]. Additionally, several statistical rules of thumb have gradually been imposed on the community, improving the development and validation of predictive models, particularly the use of a sufficient number of patients per radiomics feature, the dataset partitioning into independent training, validation and test subsets, the hyperparameter optimization and cross-validation of the algorithms and the use of objective performance metrics [160-162]. In the era of precision medicine, multiparametric imaging offers unique opportunities to characterize tumor behavior at an advanced multidimensional imaging level $[163,164]$. Interestingly, multiparametric radiomics has recently been shown to surpass single-modality procedures. In their proofof-concept study, Vallières M. and coworkers demonstrated the superiority of joint FDG PET and MRI texture features to predict the risk of lung metastases in soft tissue sarcomas [165]: in a cohort of 51 biopsy-proven sarcomas, first- and second-order radiomics features were extracted from either FDG PET, MRI (T1- and T2-weighted) or fused PET/MRI baseline data. Among all the multivariable predictive models tested, the models constructed from fused PET/MRI data surpassed those generated either from PET or PET + MRI separated scans (AUC of $0.98 \pm 0.002$, sensitivity of $0.955 \pm 0.006$, specificity of $0.926 \pm 0.004$ ). More recently, $\mathrm{Mu} \mathrm{W}$. and coworkers compared the predictive value of single-modality and fused FDG PET/CT-based radiomic signatures (baseline scans) to predict the durable clinical benefit of immune checkpoint inhibitors in advanced NSCLC patients [166]. Trained on 99 patients and validated on two independent cohorts of 47 NSCLC (retrospective) and 
48 NSCLC (prospective) patients, the predictive models, which included features generated from fused PET/CT data, were improved in all the training and test sets, reaching AUCs of 0.86 (95\% CI 0.79-0.94), 0.83 (95\% CI 0.71-0.94) and 0.81 (95\% CI 0.68-0.92), respectively.

By capturing the pooled radiomic signatures of tumors across different imaging modalities, multiparametric radiomics changes the dimensionality of analyses: the extracted features no longer represent intervoxel relationships in a modality of interest but the multidimensional tumor behavior, driven by the properties of each modality. Such a paradigm shift will probably be enhanced with fully integrated PET/MRI systems, which have been clinically available since the beginning of the 2010s [167]. In this way, rather than using standard-of-care qualitative or semiquantitative PET, CT or MRI images, one could move towards more quantitative multiparametric analyses in future practice [168]. Moreover, fully automated and miniaturized production systems for PET radiotracer use in a "doseon-demand" mode could stimulate multi-PET probe patient imaging in future clinical practice (iMiGiNE project, PMB-Alcen/SIGMAPHI/CEA).

To face the growing complexity of this arsenal of multidimensional data, the use of deep learning - a branch of machine learning using neural networks (convolutional neural networks (CNNs) in image processing) - appears to be a promising way to assist practitioners in the future. Because CNNs learn characteristics directly from raw images, feature extraction and prediction tasks can be performed jointly in an embedded process, bypassing classical handcrafted segmentation, feature selection or classification multilevel steps $[169,170]$. Moreover, two recent studies nicely illustrate the potential gain at the wholebody level of automated CNN-based detection and classification tasks in PET/CT. From 629 FDG PET/CT data (302 lung cancer and 327 lymphoma) retrospectively labeled by two nuclear medicine physicians, Sibille L. et al. trained, validated and tested a CNN research prototype (PET Assisted Reporting System PARS, Siemens Healthineers) to automatically detect and classify abnormalities (anatomic location, suspicious or nonsuspicious), reaching a classification AUC of 0.988 (95\% CI 0.982-0.994) [171]. In their study, including almost 3500 FDG PET/CT data points from patients with various malignancies/benign diseases, Kawauchi K. et al. successfully classified PET data into three predefined classes (benign, malignant, equivocal), and their $\mathrm{CNN}$ reached accuracies of $99.4,99.4$ and $87.5 \%$ at the patient level [172]. Beyond evident improvements in the entire image processing workflow, numerous technical challenges will have to be faced before clinical validation. As an example, the recent external validation of the PET Assisted Reporting System (PARS, Siemens Healthineers) [171] on two French cohorts (cohort 1: 119 cases of DLBCL; cohort 2: 430 miscellaneous cancers) showed discrepancies between the reference manual and CNNbased procedures (cohort 1: median Dice score $=0.65 ; \mathrm{ICC}_{\mathrm{TMTV}}=0.68$; cohort 2: median Dice score $=0.48 ; \mathrm{ICC}_{\mathrm{TMTV}}=0.61$ ) [173]. For multidimensional image-based decision making, the level of image dimensionality (how many modalities? how many parameters? what level of quantification?) and the optimal way to integrate this multidimensionality in the depths of CNNs [174] will also require many research investigations. Regardless, deep learning-based multidimensional quantification can pave the way for more operational and holistic cancer molecular imaging analyses at the whole-body level (Figure 10). 


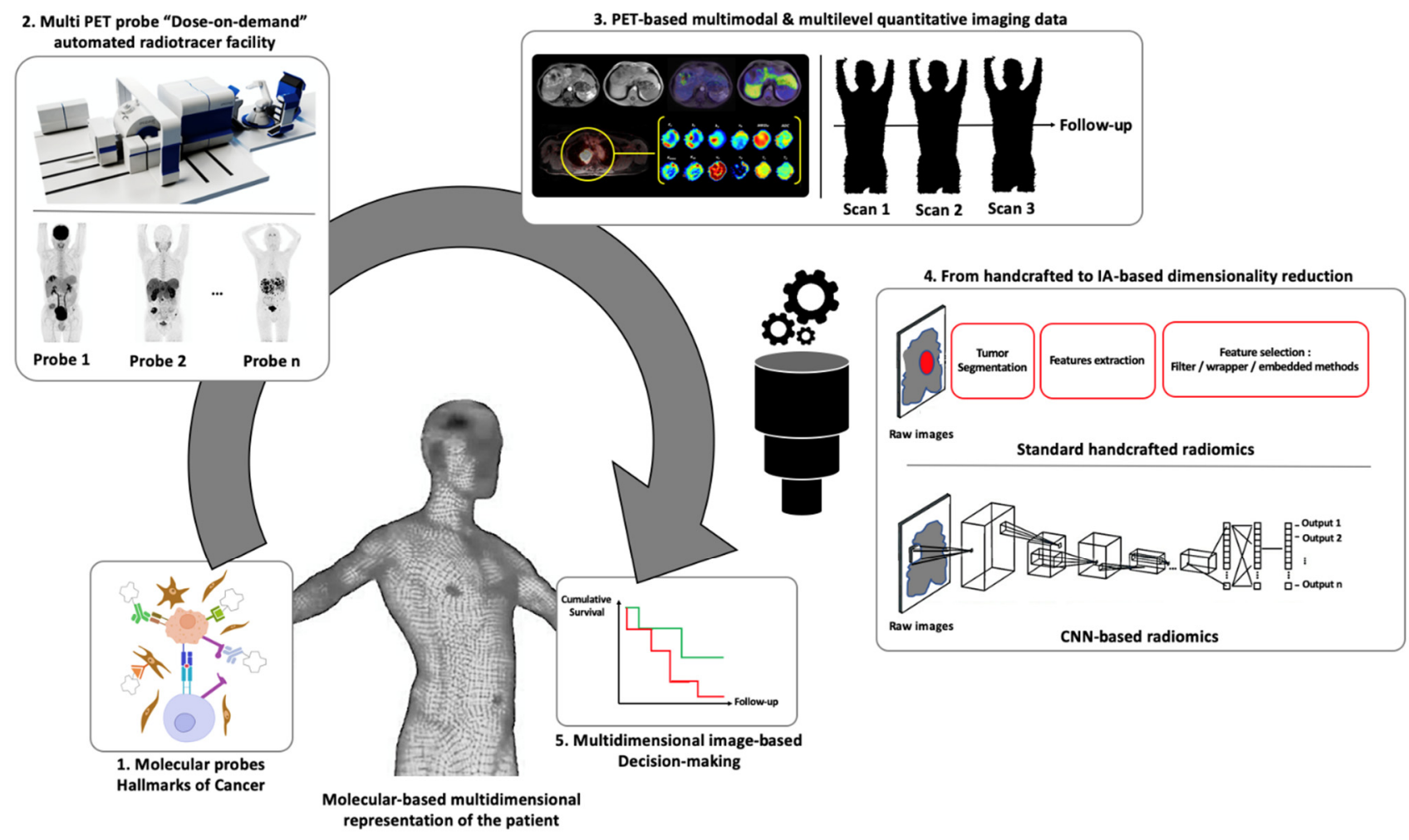

Figure 10. General overview of the potential of molecular-based multimodal imaging in the era of precision medicine: (1) Molecular probes are defined based on cancer hallmark knowledge. (2) Miniaturized automated PET radioligand production facilities could allow very fast and easy PET probe radiolabeling in future clinical practice, stimulating multiprobe PET imaging of oncological patients. (3) Static and/or dynamic multimodal PET-based acquisition procedures generate multidimensional image-based metrics at baseline and during follow-up. (4) Applications of statistical and computer sciences would facilitate the extraction and dimensionality reduction of all this information to make optimized image-based decision models (5) The panel 2 subpart of the prototypal "Dose-on-Demand" automated radiotracer facility is courtesy of Ludovic Le Meunier (PMB-Alcen, iMiGiNE project, PMB-Alcen/SIGMAPHI/CEA).

\section{Conclusions}

PET molecular imaging is a powerful imaging modality for quantifying tumor processes. After 20 years of clinical use around the world, PET/CT has proven its unique value for the diagnosis and therapeutic evaluation of many cancers. This maturity now allows us to consider a move towards more sophisticated levels of analyses in future clinical practice, boosted by the development of PET-based multimodal imaging, multiprobe radiolabeling and multidimensional data mining. A more holistic image-based representation of oncological processes becomes conceivable at the whole-body level, making PET molecular imaging a tool of choice in precision medicine for the next few years.

Author Contributions: All authors (V.D., A.I., L.G. (Léa Gomez), L.G. (Lucas Goldfarb) and F.L.B.) have directly participated in the review process and in the writing of this article. All authors have read and agreed to the published version of the manuscript.

Funding: This research received no external funding.

Institutional Review Board Statement: Not applicable.

Informed Consent Statement: Not applicable.

Data Availability Statement: Not applicable.

Acknowledgments: The authors would like to particularly thank Jérémie Calais, Martin Auerbach and Andrei Gafita (Ahmanson Translational Theranostics Division, UCLA, Los Angeles, CA, USA), 
Alizée Bouleau, Charles Truillet and Vincent Lebon (Université Paris-Saclay, CEA, CNRS, Inserm, BioMaps) and Ludovic Le Meunier (Pmb-Alcen) for their help with pictorial support.

Conflicts of Interest: The authors declare no conflict of interest.

\section{References}

1. $\quad$ van Tinteren, H.; Hoekstra, O.S.; Smit, E.F.; van den Bergh, J.H.; Schreurs, A.J.; Stallaert, R.A.; van Velthoven, P.C.; Comans, E.F.; Diepenhorst, F.W.; Verboom, P.; et al. Effectiveness of positron emission tomography in the preoperative assessment of patients with suspected non-small-cell lung cancer: The PLUS multicentre randomised trial. Lancet 2002, 359, 1388-1392. [CrossRef]

2. Lindsay, M.J.; Siegel, B.A.; Tunis, S.R.; Hillner, B.E.; Shields, A.F.; Carey, B.P.; Coleman, R.E. The National Oncologic PET Registry: Expanded medicare coverage for PET under coverage with evidence development. Am. J. Roentgenol. 2007, 188, 1109-1113. [CrossRef] [PubMed]

3. Hillner, B.E.; Siegel, B.A.; Liu, D.; Shields, A.F.; Gareen, I.F.; Hanna, L.; Stine, S.H.; Coleman, R.E. Impact of positron emission tomography/computed tomography and positron emission tomography (PET) alone on expected management of patients with cancer: Initial results from the National Oncologic PET Registry. J. Clin. Oncol. 2008, 26, 2155-2161. [CrossRef] [PubMed]

4. Hricak, H.; Abdel-Wahab, M.; Atun, R.; Lette, M.M.; Paez, D.; Brink, J.A.; Donoso-Bach, L.; Frija, G.; Hierath, M.; Holmberg, O.; et al. Medical imaging and nuclear medicine: A Lancet Oncology Commission. Lancet Oncol. 2021. [CrossRef]

5. Katsari, K.; Penna, D.; Arena, V.; Polverari, G.; Ianniello, A.; Italiano, D.; Milani, R.; Roncacci, A.; Illing, R.O.; Pelosi, E. Artificial intelligence for reduced dose 18F-FDG PET examinations: A real-world deployment through a standardized framework and business case assessment. EJNMMI Phys. 2021, 8, 25. [CrossRef] [PubMed]

6. Boellaard, R. Standards for PET image acquisition and quantitative data analysis. J. Nucl. Med. 2009, 50, 11S-20S. [CrossRef] [PubMed]

7. Aide, N.; Lasnon, C.; Veit-Haibach, P.; Sera, T.; Sattler, B.; Boellaard, R. EANM/EARL harmonization strategies in PET quantification: From daily practice to multicentre oncological studies. Eur. J. Nucl. Med. Mol. Imaging 2017, 44, 17-31. [CrossRef]

8. Boellaard, R.; Delgado-Bolton, R.; Oyen, W.J.G.; Giammarile, F.; Tatsch, K.; Eschner, W.; Verzijlbergen, F.J.; Barrington, S.F.; Pike, L.C.; Weber, W.A.; et al. FDG PET/CT: EANM procedure guidelines for tumour imaging: Version 2.0. Eur. J. Nucl. Med. Mol. Imaging 2015, 42, 328-354. [CrossRef]

9. Bar-Sever, Z.; Biassoni, L.; Shulkin, B.; Kong, G.; Hofman, M.S.; Lopci, E.; Manea, I.; Koziorowski, J.; Castellani, R.; Boubaker, A.; et al. Guidelines on nuclear medicine imaging in neuroblastoma. Eur. J. Nucl. Med. Mol. Imaging 2018, 45, 2009-2024. [CrossRef]

10. Law, I.; Albert, N.L.; Arbizu, J.; Boellaard, R.; Drzezga, A.; Galldiks, N.; la Fougère, C.; Langen, K.J.; Lopci, E.; Lowe, V.; et al. Joint EANM/EANO/RANO practice guidelines/SNMMI procedure standards for imaging of gliomas using PET with radiolabelled amino acids and [18F]FDG: Version 1.0. Eur. J. Nucl. Med. Mol. Imaging 2019, 46, 540-557. [CrossRef]

11. Shankar, L.K.; Hoffman, J.M.; Bacharach, S.; Graham, M.M.; Karp, J.; Lammertsma, A.A.; Larson, S.; Mankoff, D.A.; Siegel, B.A.; Abbeele, A.V.D.; et al. Consensus recommendations for the use of 18F-FDG PET as an indicator of therapeutic response in patients in National Cancer Institute Trials. J. Nucl. Med. 2006, 47, 1059-1066. [PubMed]

12. Barrington, S.F.; Mikhaeel, N.G.; Kostakoglu, L.; Meignan, M.; Hutchings, M.; Müeller, S.P.; Schwartz, L.H.; Zucca, E.; Fisher, R.I.; Trotman, J.; et al. Role of Imaging in the Staging and Response Assessment of Lymphoma: Consensus of the International Conference on Malignant Lymphomas Imaging Working Group. J. Clin. Oncol. 2014, 32, 3048-3058. [CrossRef]

13. Wirth, A.; Foo, M.; Seymour, J.F.; MacManus, M.P.; Hicks, R.J. Impact of [18F] Fluorodeoxyglucose Positron Emission Tomography on Staging and Management of Early-Stage Follicular Non-Hodgkin Lymphoma. Int. J. Radiat. Oncol. Biol. Phys. 2008, 71, 213-219. [CrossRef] [PubMed]

14. Reinhardt, M.J.; Joe, A.Y.; Jaeger, U.; Hubetr, A.; Matthies, A.; Bucerius, J.; Roedel, R.; Strunk, H.; Bieber, T.; Biersack, H.-J.; et al. Diagnostic Performance of Whole Body Dual Modality ${ }^{18}$ F-FDG PET/CT Imaging for N- and M-Staging of Malignant Melanoma: Experience With 250 Consecutive Patients. J. Clin. Oncol. 2006, 24, 1178-1187. [CrossRef]

15. Gould, M.K.; Maclean, C.C.; Kuschner, W.G.; Rydzak, C.E.; Owens, D.K. Accuracy of Positron Emission Tomography for Diagnosis of Pulmonary Nodules and Mass Lesions: A Meta-analysis. JAMA 2001, 285, 914. [CrossRef]

16. Kolodziejczyk, M.; Kepka, L.; Dziuk, M.; Zawadzka, A.; Szalus, N.; Gizewska, A.; Bujko, K. Impact of [18F]Fluorodeoxyglucose PET-CT Staging on Treatment Planning in Radiotherapy Incorporating Elective Nodal Irradiation for Non-Small-Cell Lung Cancer: A Prospective Study. Int. J. Radiat. Oncol. Biol. Phys. 2011, 80, 1008-1014. [CrossRef]

17. King, K.S.; Chen, C.C.; Alexopoulos, D.K.; Whatlety, M.A.; Reynolds, J.C.; Patronas, N.; Ling, A.; Adams, K.T.; Xekouki, P.; Lando, H.; et al. Functional Imaging of $S D H x$-Related Head and Neck Paragangliomas: Comparison of ${ }^{18} \mathrm{~F}-$ Fluorodihydroxyphenylalanine, ${ }^{18}$ F-Fluorodopamine, ${ }^{18}$ F-Fluoro-2-Deoxy-D-Glucose PET, ${ }^{123}$ I-Metaiodobenzylguanidine Scintigraphy, and ${ }^{111}$ In-Pentetreotide Scintigraphy. J. Clin. Endocrinol. Metab. 2011, 96, 2779-2785. [CrossRef] [PubMed]

18. Treglia, G.; Cocciolillo, F.; de Waure, C.; Di Nardo, F.; Gualano, M.R.; Castaldi, P.; Rufini, V.; Giordano, A. Diagnostic performance of 18F-dihydroxyphenylalanine positron emission tomography in patients with paraganglioma: A meta-analysis. Eur. J. Nucl. Med. Mol. Imaging 2012, 39, 1144-1153. [CrossRef]

19. Taieb, D.; Neumann, H.; Rubello, D.; Al-Nahhas, A.; Guillet, B.; Hindie, E. Modern Nuclear Imaging for Paragangliomas: Beyond SPECT. J. Nucl. Med. 2012, 53, 264-274. [CrossRef] 
20. Zamagni, E.; Nanni, C.; Dozza, L.; Carlier, T.; Tacchetti, P.; Versari, A.; Chauvie, S.; Gallamini, A.; Attal, M.; Gamberi, B.; et al. Standardization of 18F-FDG PET/CT According to Deauville Criteria for MRD Evaluation in Newly Diagnosed Transplant Eligible Multiple Myeloma Patients: Joined Analysis of Two Prospective Randomized Phase III Trials. Blood 2018, $132,257$. [CrossRef]

21. Kubota, K.; Matsuzawa, T.; Ito, M.; Ito, K.; Fujiwara, T.; Albe, Y.; Yoshioka, S.; Fukuda, H.; Hatazawa, J.; Iwata, R. Lung tumor imaging by positron emission tomography using C-11 L-methionine. J. Nucl. Med. 1985, 26, 37-42. [PubMed]

22. Thie, J.A. Understanding the standardized uptake value, its methods, and implications for usage. J. Nucl. Med. 2004, 45, 1431-1434.

23. Boellaard, R.; Krak, N.C.; Hoekstra, O.S.; Lammertsma, A.A. Effects of noise, image resolution, and ROI definition on the accuracy of standard uptake values: A simulation study. J. Nucl. Med. 2004, 45, 1519-1527.

24. Foster, B.; Bagci, U.; Mansoor, A.; Xu, Z.; Mollura, D.J. A review on segmentation of positron emission tomography images. Comput. Biol. Med. 2014, 50, 76-96. [CrossRef]

25. Ott, K.; Weber, W.A.; Lordick, F.; Becker, K.; Busch, R.; Herrmann, K.; Wieder, H.; Fink, U.; Schwaiger, M.; Siewert, J.-R. Metabolic imaging predicts response, survival, and recurrence in adenocarcinomas of the esophagogastric junction. J. Clin. Oncol. 2006, 24, 4692-4698. [CrossRef]

26. Cascini, G.L.; Avallone, A.; Delrio, P.; Guida, C.; Tatangetlo, F.; Marone, P.; Aloj, L.; De Martinis, F.; Comella, P.; Parisi, V.; et al. 18F-FDG PET is an early predictor of pathologic tumor response to preoperative radiochemotherapy in locally advanced rectal cancer. J. Nucl. Med. 2006, 47, 1241-1248.

27. Nols, N.; Mounier, N.; Bouazza, S.; Lhommel, R.; Costantini, S.; Borght, T.V.; Vekemans, M.-C.; Sonet, A.; Bosly, A.; Michaux, L.; et al. Quantitative and qualitative analysis of metabolic response at interim positron emission tomography scan combined with International Prognostic Index is highly predictive of outcome in diffuse large B-cell lymphoma. Leuk. Lymphoma 2014, 55, 773-780. [CrossRef]

28. Lin, C.; Itti, E.; Haioun, C.; Petegnief, Y.; Luciani, A.; Dupuis, J.; Paone, G.; Talbot, J.-N.; Rahmouni, A.; Meignan, M. Early 18F-FDG PET for Prediction of Prognosis in Patients with Diffuse Large B-Cell Lymphoma: SUV-Based Assessment Versus Visual Analysis. J. Nucl. Med. 2007, 48, 1626-1632. [CrossRef] [PubMed]

29. Fuertes, S.; Setoain, X.; Lopez-Guillermo, A.; Carrasco, J.-L.; Rodriguetz, S.; Roviral, J.; Pons, F. Interim FDG PET/CT as a prognostic factor in diffuse large B-cell lymphoma. Eur. J. Nucl. Med. Mol. Imaging 2013, 40, 496-504. [CrossRef]

30. Casasnovas, R.-O.; Meignan, M.; Berriolo-Riedinger, A.; Bardet, S.; Julian, A.; Thieblemont, C.; Vera, P.; Bologna, S.; Brière, J.; Jais, J.-P.; et al. SUVmax reduction improves early prognosis value of interim positron emission tomography scans in diffuse large B-cell lymphoma. Blood 2011, 118, 37-43. [CrossRef] [PubMed]

31. Stroobants, S.; Goeminne, J.; Seegers, M.; Dimitrijevic, S.; Dupont, P.; Nuyts, J.; Martens, M.; Borne, B.V.D.; Cole, P.; Sciot, R.; et al. 18FDG-Positron emission tomography for the early prediction of response in advanced soft tissue sarcoma treated with imatinib mesylate (Glivec ${ }^{\circledR}$ ). Eur. J. Cancer 2003, 39, 2012-2020. [CrossRef]

32. Prior, J.O.; Montemurro, M.; Orcurto, M.-V.; Michielin, O.; Luthi, F.; Benhattar, J.; Guillou, L.; Elsig, V.; Stupp, R.; Delaloye, A.B.; et al. Early Prediction of Response to Sunitinib After Imatinib Failure by ${ }^{18}$ F-Fluorodeoxyglucose Positron Emission Tomography in Patients With Gastrointestinal Stromal Tumor. J. Clin. Oncol. 2009, 27, 439-445. [CrossRef] [PubMed]

33. Usmani, S.Z.; Mitchell, A.; Waheed, S.; Crowley, J.; Hoering, A.; Petty, N.; Brown, T.; Bartel, T.; Anaissie, E.; Van Rhee, F.; et al. Prognostic implications of serial 18-fluoro-deoxyglucose emission tomography in multiple myeloma treated with total therapy 3. Blood 2013, 121, 1819-1823. [CrossRef] [PubMed]

34. McDonald, J.E.; Kessler, M.M.; Gardner, M.W.; Buros, A.F.; Ntambi, J.A.; Waheed, S.; Van Rhee, F.; Zangari, M.; Heuck, C.J.; Petty, N.; et al. Assessment of Total Lesion Glycolysis by ${ }^{18}$ F FDG PET/CT Significantly Improves Prognostic Value of GEP and ISS in Myeloma. Clin. Cancer Res. 2017, 23, 1981-1987. [CrossRef]

35. Patlak, C.S.; Blasberg, R.G. Graphical Evaluation of Blood-to-Brain Transfer Constants from Multiple-Time Uptake Data. Generalizations. J. Cereb. Blood Flow. Metab. 1985, 5, 584-590. [CrossRef]

36. Morris, E.D.; Endres, C.J.; Schmidt, K.C.; Christian, B.T.; Muzic, R.F.; Fisher, R.E. Kinetic Modeling in Positron Emission Tomography. In Emission Tomography; Elsevier: Amsterdam, The Netherlands, 2004; pp. 499-540. [CrossRef]

37. Dimitrakopoulou-Strauss, A.; Pan, L.; Sachpekidis, C. Kinetic modeling and parametric imaging with dynamic PET for oncological applications: General considerations, current clinical applications, and future perspectives. Eur. J. Nucl. Med. Mol. Imaging 2021, 48, 21-39. [CrossRef]

38. Sokoloff, L.; Reivich, M.; Kennedy, C.; Rosiers, M.H.D.; Patlak, C.S.; Pettigrew, K.D.; Salkurada, O.; Shinohara, M. The $\left[{ }^{14} \mathrm{C}\right]$ Deoxyglucose Method for the Measurement of Local Cerebral Glucose Utilization: Theory, Procedure, and Normal Values in the Conscious and Anesthetized Albino rat. J. Neurochem. 1977, 28, 897-916. [CrossRef]

39. Badawi, R.D.; Shi, H.; Hu, P.; Chen, S.; Xu, T.; Price, P.M.; Ding, Y.; Spencer, B.A.; Nardo, L.; Liu, W.; et al. First Human Imaging Studies with the EXPLORER Total-Body PET Scanner. J. Nucl. Med. 2019, 60, 299-303. [CrossRef]

40. Karp, J.S.; Viswanath, V.; Geagan, M.J.; Muehllehner, G.; Pantel, A.R.; Parma, M.J.; Perkins, A.E.; Schmall, J.P.; Werner, M.E.; Daube-Witherspoon, M.E. PennPET Explorer: Design and Preliminary Performance of a Whole-Body Imager. J. Nucl. Med. 2020, 61, 136-143. [CrossRef]

41. Zhang, X.; Xie, Z.; Berg, E.; Judenhofer, M.S.; Liu, W.; Xu, T.; Ding, Y.; Lv, Y.; Dong, Y.; Deng, Z.; et al. Total-Body Dynamic Reconstruction and Parametric Imaging on the uEXPLORER. J. Nucl. Med. 2020, 61, 285-291. [CrossRef] 
42. Mullani, N.A.; Herbst, R.S.; O’Neil, R.G.; Gould, K.L.; Barron, B.J.; Abbruzzese, J.L. Tumor Blood Flow Measured by PET Dynamic Imaging of First-Pass 18F-FDG Uptake: A Comparison with 15O-Labeled Water-Measured Blood Flow. J. Nucl. Med. 2008, 49, 517-523. [CrossRef]

43. Cochet, A.; Pigeonnat, S.; Khoury, B.; Vrigneaud, J.-M.; Touzery, C.; Berriolo-Riedinger, A.; Dygai-Cochet, I.; Toubeau, M.; Humbert, O.; Coudert, B.; et al. Evaluation of Breast Tumor Blood Flow with Dynamic First-Pass 18F-FDG PET/CT: Comparison with Angiogenesis Markers and Prognostic Factors. J. Nucl. Med. 2012, 53, 512-520. [CrossRef]

44. Meikle, S.R.; Sossi, V.; Roncali, E.; Cherry, S.R.; Banati, R.; Mankoff, D.A.; Jones, T.; James, M.L.; Sutcliffe, J.; Ouyang, J.; et al. Quantitative PET in the 2020s: A Roadmap. Phys. Med. Biol. 2020. [CrossRef]

45. Eisenhauer, E.A.; Therasse, P.; Bogaerts, J.; Schwartz, L.H.; Sargent, D.; Ford, R.; Dancey, J.; Arbuck, S.; Gwyther, S.; Mooney, M. New response evaluation criteria in solid tumours: Revised RECIST guideline (version 1.1). Eur. J. Cancer 2009, 45, 228-247. [CrossRef] [PubMed]

46. Young, H.; Baum, R.; Cremerius, U.; Herholz, K.; Hoekstra, O.; Lammertsma, A.; Pruim, J.; Price, P. Measurement of clinical and subclinical tumour response using $\left[{ }^{18} \mathrm{~F}\right]$-fluorodeoxyglucose and positron emission tomography: Review and 1999 EORTC recommendations. Eur. J. Cancer 1999, 35, 1773-1782. [CrossRef]

47. Tylski, P.; Stute, S.; Grotus, N.; Doyeux, K.; Hapdey, S.; Gardin, I.; Vanderlinden, B.; Buvat, I. Comparative assessment of methods for estimating tumor volume and standardized uptake value in (18)F-FDG PET. J. Nucl. Med. 2010, 51, 268-276. [CrossRef]

48. Wahl, R.L.; Jacene, H.; Kasamon, Y.; Lodge, M.A. From RECIST to PERCIST: Evolving Considerations for PET Response Criteria in Solid Tumors. J. Nucl. Med. 2009, 50, 122S-150S. [CrossRef]

49. Riedl, C.C.; Pinker, K.; Ulaner, G.A.; Ong, L.T.; Baltzer, P.; Jochelson, M.S.; McArthur, H.L.; Gönen, M.; Dickler, M.; Weber, W.A. Comparison of FDG-PET/CT and contrast-enhanced CT for monitoring therapy response in patients with metastatic breast cancer. Eur. J. Nucl. Med. Mol. Imaging 2017, 44, 1428-1437. [CrossRef]

50. Yanagawa, M.; Tatsumi, M.; Miyata, H.; Morii, E.; Tomiyama, N.; Waltabe, T.; Isohashi, K.; Kato, H.; Shimosegawa, E.; Yamasaki, M.; et al. Evaluation of Response to Neoadjuvant Chemotherapy for Esophageal Cancer: PET Response Criteria in Solid Tumors Versus Response Evaluation Criteria in Solid Tumors. J. Nucl. Med. 2012, 53, 872-880. [CrossRef]

51. Koshkin, V.S.; Bolejack, V.; Schwartz, L.H.; Wahl, R.L.; Chugh, R.; Reinke, D.K.; Zhao, B.; O, J.H.; Patel, S.R.; Schuetze, S.M.; et al. Assessment of Imaging Modalities and Response Metrics in Ewing Sarcoma: Correlation with Survival. J. Clin. Oncol. 2016, 34, 3680-3685. [CrossRef] [PubMed]

52. Shang, J.; Ling, X.; Zhang, L.; Tang, Y.; Xiao, Z.; Chetng, Y.; Guo, B.; Gong, J.; Huang, L.; Xu, H. Comparison of RECIST, EORTC criteria and PERCIST for evaluation of early response to chemotherapy in patients with non-small-cell lung cancer. Eur. J. Nucl. Med. Mol. Imaging 2016, 43, 1945-1953. [CrossRef]

53. Ding, Q.; Cheng, X.; Yang, L.; Zhang, Q.; Chen, J.; Li, T.; Shi, H. PET/CT evaluation of response to chemotherapy in non-small cell lung cancer: PET response criteria in solid tumors (PERCIST) versus response evaluation criteria in solid tumors (RECIST). J. Thorac. Dis. 2014, 6, 677-683. [CrossRef]

54. Champiat, S.; Dercle, L.; Ammari, S.; Massard, C.; Hollebecque, A.; Postel-Vinay, S.; Chaput, N.; Eggermont, A.M.; Marabelle, A.; Soria, J.-C. Hyperprogressive Disease Is a New Pattern of Progression in Cancer Patients Treated by Anti-PD-1/PD-L1. Clin. Cancer Res. 2017, 23, 1920-1928. [CrossRef]

55. Goldfarb, L.; Duchemann, B.; Chouahnia, K.; Zelek, L.; Soussan, M. Monitoring anti-PD-1-based immunotherapy in non-small cell lung cancer with FDG PET: Introduction of iPERCIST. EJNMMI Res. 2019, 9, 8. [CrossRef] [PubMed]

56. Cho, S.Y.; Lipson, E.J.; Im, H.-J.; Rowet, S.P.; Gonzalez, E.M.; Blackford, A.; Chirindel, A.; Pardoll, D.M.; Topalian, S.L.; Wahl, R.L. Prediction of Response to Immune Checkpoint Inhibitor Therapy Using Early-Time-Point ${ }^{18}$ F-FDG PET/CT Imaging in Patients with Advanced Melanoma. J. Nucl. Med. 2017, 58, 1421-1428. [CrossRef] [PubMed]

57. Anwar, H.; Sachpekidis, C.; Winkler, J.; Kopp-Schnetider, A.; Haberkorn, U.; Hassel, J.C.; Dimitrakopoulou-Strauss, A. Absolute number of new lesions on 18F-FDG PET/CT is more predictive of clinical response than SUV changes in metastatic melanoma patients receiving ipilimumab. Eur. J. Nucl. Med. Mol. Imaging 2018, 45, 376-383. [CrossRef] [PubMed]

58. Sachpekidis, C.; Anwar, H.; Winkler, J.; Kopp-Schnetider, A.; Larribere, L.; Haberkorn, U.; Hassel, J.C.; Dimitrakopoulou-Strauss, A. The role of interim 18F-FDG PET/CT in prediction of response to ipilimumab treatment in metastatic melanoma. Eur. J. Nucl. Med. Mol. Imaging 2018, 45, 1289-1296. [CrossRef]

59. Aide, N.; Hicks, R.J.; Le Tourneau, C.; Lheureux, S.; Fanti, S.; Lopci, E. FDG PET/CT for assessing tumour response to immunotherapy: Report on the EANM symposium on immune modulation and recent review of the literature. Eur. J. Nucl. Med. Mol. Imaging 2019, 46, 238-250. [CrossRef]

60. Martin de Fremont, G.; Belkhir, R.; Henry, J.; Voisin, A.L.; Lambotte, O.; Besson, F.L.; Mariette, X.; Nocturne, G. Features of polymyalgia rheumatica-like syndrome after immune checkpoint inhibitor therapy. Ann. Rheum. Dis. 2020. [CrossRef]

61. Seban, R.-D.; Nemer, J.S.; Marabelle, A.; Yeh, R.; Deutsch, E.; Ammari, S.; Moya-Plana, A.; Mokrane, F.-Z.; Gartrell, R.D.; Finkel, G.; et al. Prognostic and theranostic 18F-FDG PET biomarkers for anti-PD1 immunotherapy in metastatic melanoma: Association with outcome and transcriptomics. Eur. J. Nucl. Med. Mol. Imaging 2019, 46, 2298-2310. [CrossRef]

62. Friedman, C.F.; Proverbs-Singh, T.A.; Postow, M.A. Treatment of the Immune-Related Adverse Effects of Immune Checkpoint Inhibitors: A Review. JAMA Oncol. 2016, 2, 1346. [CrossRef] 
63. Haratani, K.; Hayashi, H.; Chiba, Y.; Kudo, K.; Yonesaka, K.; Kato, R.; Kalneda, H.; Hasegawa, Y.; Tanaka, K.; Takeda, M.; et al. Association of Immune-Related Adverse Events with Nivolumab Efficacy in Non-Small-Cell Lung Cancer. JAMA Oncol. 2018, 4, 374. [CrossRef] [PubMed]

64. Cheson, B.D.; Pfistner, B.; Juweid, M.E.; Gascoyne, R.D.; Specht, L.; Horning, S.J.; Coiffier, B.; Fisher, R.I.; Hagenbeek, A.; Zucca, E.; et al. Revised Response Criteria for Malignant Lymphoma. J. Clin. Oncol. 2007, 25, 579-586. [CrossRef] [PubMed]

65. Cheson, B.D.; Horning, S.J.; Coiffier, B.; Shipp, M.A.; Fisher, R.I.; Connors, J.M.; Lister, T.A.; Vose, J.; Grillo-López, A.; Hagenbeek, A.; et al. Report of an International Workshop to Standardize Response Criteria for Non-Hodgkin's Lymphomas. J. Clin. Oncol. 1999, 17, 1244. [CrossRef] [PubMed]

66. Cheson, B.D.; Fisher, R.I.; Barrington, S.F.; Cavalli, F.; Schwartz, L.H.; Zucca, E.; Lister, T.A. Recommendations for Initial Evaluation, Staging, and Response Assessment of Hodgkin and Non-Hodgkin Lymphoma: The Lugano Classification. J. Clin. Oncol. 2014, 32, 3059-3067. [CrossRef]

67. Itti, E.; Meignan, M.; Berriolo-Riedinger, A.; Biggi, A.; Cashen, A.F.; Véra, P.; Tilly, H.; Siegel, B.A.; Gallamini, A.; Casasnovas, R.-O.; et al. An international confirmatory study of the prognostic value of early PET/CT in diffuse large B-cell lymphoma: Comparison between Deauville criteria and $\Delta$ SUVmax. Eur. J. Nucl. Med. Mol. Imaging 2013, 40, 1312-1320. [CrossRef]

68. Yuan, L.; Kreissl, M.C.; Su, L.; Wu, Z.; Hacker, M.; Liu, J.; Zhang, X.; Bo, Y.; Zhang, H.; Li, X.; et al. Prognostic Analysis of Interim 18F-FDG PET/CT in Patients with Diffuse Large B Cell Lymphoma after One Cycle versus Two Cycles of Chemotherapy. Eur. J. Nucl. Med. Mol. Imaging 2019, 46, 478-488. [CrossRef] [PubMed]

69. Schöder, H.; Polley, M.-Y.C.; Knopp, M.V.; Hall, N.C.; Kostakoglu, L.; Zhang, J.; Higley, H.R.; Kelloff, G.; Liu, H.; Zelenetz, A.D.; et al. Prognostic value of interim FDG-PET in diffuse large cell lymphoma: Results from the CALGB 50303 Clinical Trial. Blood 2020, 135, 2224-2234. [CrossRef]

70. Casasnovas, R.-O.; Ysebaert, L.; Thieblemont, C.; Bachy, E.; Feugier, P.; Delmer, A.; Tricot, S.; Gabarre, J.; Andre, M.; Fruchart, C.; et al. FDG-PET-driven consolidation strategy in diffuse large B-cell lymphoma: Final results of a randomized phase 2 study. Blood 2017, 130, 1315-1326. [CrossRef]

71. Dührsen, U.; Müller, S.; Hertenstein, B.; Thomssen, H.; Kotzerke, J.; Mesters, R.; Berdel, W.E.; Franzius, C.; Kroschinsky, F.; Weckesser, M.; et al. Positron Emission Tomography-Guided Therapy of Aggressive Non-Hodgkin Lymphomas (PETAL): A Multicenter, Randomized Phase III Trial. J. Clin. Oncol. 2018, 36, 2024-2034. [CrossRef]

72. Cheson, B.D.; Ansell, S.; Schwartz, L.; Gordon, L.I.; Aldvani, R.; Jacene, H.A.; Hoos, A.; Barrington, S.F.; Armand, P. Refinement of the Lugano Classification lymphoma response criteria in the era of immunomodulatory therapy. Blood 2016, 128, 2489-2496. [CrossRef] [PubMed]

73. Younes, A.; Hilden, P.; Coiffier, B.; Hagenbeek, A.; Salles, G.; Wilson, W.; Seymour, J.F.; Kelly, K.; Gribben, J.; Pfreunschuh, M.; et al. International Working Group consensus response evaluation criteria in lymphoma (RECIL 2017). Ann. Oncol. 2017, 28, 1436-1447. [CrossRef]

74. Beksac, M.; Gunduz, M.; Ozen, M.; Bakanay Ozturk, S.M.; Kucuk, O.; Ozkan, E. Impact of PET-CT Response on Survival Parameters Following Autologous Stem Cell Transplantation Among Patients with Multiple Myeloma: Comparison of Two Cut-Off Values. Blood 2014, 124, 3983. [CrossRef]

75. Rajkumar, S.V.; Dimopoulos, M.A.; Palumbo, A.; Blade, J.; Merlini, G.; Mateos, M.-V.; Kumar, S.; Hillengass, J.; Kastritis, E.; Richardson, P.; et al. International Myeloma Working Group updated criteria for the diagnosis of multiple myeloma. Lancet Oncol. 2014, 15, e538-e548. [CrossRef]

76. Fonti, R.; Larobina, M.; Del Vecchio, S.; De Luca, S.; Fabbricini, R.; Catalano, L.; Pane, F.; Salvatore, M.; Pace, L. Metabolic Tumor Volume Assessed by 18F-FDG PET/CT for the Prediction of Outcome in Patients with Multiple Myeloma. J. Nucl. Med. 2012, 53, 1829-1835. [CrossRef] [PubMed]

77. Nanni, C.; Zamagni, E.; Versari, A.; Chauviet, S.; Bianchi, A.; Rensi, M.; Bellò, M.; Rambaldi, I.; Gallamini, A.; Patriarca, F.; et al Image interpretation criteria for FDG PET/CT in multiple myeloma: A new proposal from an Italian expert panel. IMPeTUs (Italian Myeloma criteria for PET USe). Eur. J. Nucl. Med. Mol. Imaging 2016, 43, 414-421. [CrossRef]

78. Modlin, I.M.; Lye, K.D.; Kidd, M. A 5-decade analysis of 13,715 carcinoid tumors. Cancer 2003, 97, 934-959. [CrossRef]

79. Krenning, E.P.; Breeman, W.A.P.; Kooij, P.P.M.; Lameris, J.; Bakketr, W.; Koper, J.; Ausema, L.; Reubi, J.; Lamberts, S. Localisation of endocrine-related tumours with radioiodinated analogue of somatostatin. Lancet 1989, 333, 242-244. [CrossRef]

80. Krenning, E.P.; Kwekkeboom, D.J.; Bakker, W.H.; Van Hagen, M.; Postema, P.; De Jong, M.; Reubi, J.-C.; Visser, T.; Reijs, A.; Hofland, L.; et al. Somatostatin receptor scintigraphy with [111In-DTPA-d-Phe1]- and [123I-Tyr3]-octreotide: The Rotterdam experience with more than 1000 patients. Eur. J. Nucl. Med. 1993, 20, 716-731. [CrossRef]

81. Hofmann, M.; Maecke, H.; Börner, A.; Wetckesser, E.; Schöffski, P.; Oei, M.; Schumacher, J.; Henze, M.; Heppeler, A.; Meyer, J.; et al. Biokinetics and imaging with the somatostatin receptor PET radioligand 68Ga-DOTATOC: Preliminary data. Eur. J. Nucl. Med. 2001, 28, 1751-1757. [CrossRef]

82. Poeppel, T.D.; Binse, I.; Petersenn, S.; Lahner, H.; Schott, M.; Alntoch, G.; Brandau, W.; Bockisch, A.; Boy, C. 68Ga-DOTATOC Versus 68Ga-DOTATATE PET/CT in Functional Imaging of Neuroendocrine Tumors. J. Nucl. Med. 2011, 52, 1864-1870. [CrossRef] [PubMed]

83. Velikyan, I.; Sundin, A.; Sorensen, J.; Lubberink, M.; Sandström, M.; Garske-Román, U.; Lundqvist, H.; Granberg, D.; Eriksson, B. Quantitative and Qualitative Intrapatient Comparison of 68Ga-DOTATOC and 68Ga-DOTATATE: Net Uptake Rate for Accurate Quantification. J. Nucl. Med. 2014, 55, 204-210. [CrossRef] [PubMed] 
84. Geijer, H.; Breimer, L.H. Somatostatin receptor PET/CT in neuroendocrine tumours: Update on systematic review and metaanalysis. Eur. J. Nucl. Med. Mol. Imaging 2013, 40, 1770-1780. [CrossRef] [PubMed]

85. Van Binnebeek, S.; Vanbilloen, B.; Baete, K.; Terwinghe, C.; Koole, M.; Mottaghy, F.M.; Clement, P.M.; Mortelmans, L.; Bogaerts, K.; Haustermans, K.; et al. Comparison of diagnostic accuracy of 111In-pentetreotide SPECT and 68Ga-DOTATOC PET/CT: A lesion-by-lesion analysis in patients with metastatic neuroendocrine tumours. Eur. Radiol. 2016, 26, 900-909. [CrossRef] [PubMed]

86. Sundin, A.; Arnold, R.; Baudin, E.; Cwikla, J.B.; Eriksson, B.; Fanti, S.; Fazio, N.; Giammarile, F.; Hicks, R.J.; Kjaer, A. ENETS Consensus Guidelines for the Standards of Care in Neuroendocrine Tumors: Radiological, Nuclear Medicine and Hybrid Imaging. Neuroendocrinology 2017, 105, 212-244. [CrossRef]

87. Shah, M.H.; Goldner, W.S.; Halfdanarson, T.R.; Bergsland, E.; Berlin, J.D.; Halperin, D.; Chan, J.; Kulke, M.H.; Benson, A.B.; Blaszkowsky, L.S.; et al. NCCN Guidelines Insights: Neuroendocrine and Adrenal Tumors, Version 2.2018. J. Natl. Compr. Cancer Netw. 2018, 16, 693-702. [CrossRef]

88. Strosberg, J.; El-Haddad, G.; Wolin, E.; Hendifar, A.; Yao, J.; Chasen, B.; Mittra, E.; Kunz, P.L.; Kulke, M.H.; Jacene, H.; et al. Phase 3 Trial of ${ }^{177}$ Lu-Dotatate for Midgut Neuroendocrine Tumors. N. Engl. J. Med. 2017, 376, 125-135. [CrossRef]

89. Garcia-Carbonero, R.; Sorbye, H.; Baudin, E.; Raymond, E.; Wiedenmann, B.; Niederle, B.; Sedlackova, E.; Toumpanakis, C.; Anlauf, M.; Cwikla, J.B.; et al. ENETS Consensus Guidelines for High-Grade Gastroenteropancreatic Neuroendocrine Tumors and Neuroendocrine Carcinomas. Neuroendocrinology 2016, 103, 186-194. [CrossRef]

90. Basturk, O.; Yang, Z.; Tang, L.H.; Hruban, R.H.; Adsay, V.; McCall, C.M.; Krasinskas, A.M.; Jang, K.-T.; Frankel, W.L.; Balci, S.; et al. The High-grade (WHO G3) Pancreatic Neuroendocrine Tumor Category Is Morphologically and Biologically Heterogenous and Includes Both Well Differentiated and Poorly Differentiated Neoplasms. Am. J. Surg. Pathol. 2015, 39, 683-690. [CrossRef]

91. Demirci, E.; Kabasakal, L.; Toklu, T.; Ocak, M.; Şahin, O.E.; Alan-Selcuk, N.; Araman, A. 177Lu-DOTATATE therapy in patients with neuroendocrine tumours including high-grade (WHO G3) neuroendocrine tumours: Response to treatment and long-term survival update. Nucl. Med. Commun. 2018, 39, 789-796. [CrossRef]

92. Severi, S.; Nanni, O.; Bodei, L.; Sansovini, M.; Ianniello, A.; Nicoletti, S.; Scarpi, E.; Matteucci, F.; Gilardi, L.; Paganelli, G. Role of 18FDG PET/CT in patients treated with 177Lu-DOTATATE for advanced differentiated neuroendocrine tumours. Eur. J. Nucl. Med. Mol. Imaging 2013, 40, 881-888. [CrossRef] [PubMed]

93. Bahri, H.; Laurence, L.; Edeline, J.; Leghzali, H.; Devillers, A.; Raoul, J.-L.; Cuggia, M.; Mesbah, H.; Clement, B.; Boucher, E.; et al. High Prognostic Value of 18F-FDG PET for Metastatic Gastroenteropancreatic Neuroendocrine Tumors: A Long-Term Evaluation. J. Nucl. Med. 2014, 55, 1786-1790. [CrossRef] [PubMed]

94. Bray, F.; Ferlay, J.; Soerjomataram, I.; Siegel, R.L.; Torre, L.A.; Jemal, A. Global cancer statistics 2018: GLOBOCAN estimates of incidence and mortality worldwide for 36 cancers in 185 countries. CA Cancer J. Clin. 2018, 68, 394-424. [CrossRef] [PubMed]

95. Evangelista, L.; Zattoni, F.; Guttilla, A.; Saladini, G.; Zattoni, F.; Colletti, P.M.; Rubello, D. Choline PET or PET/CT and Biochemical Relapse of Prostate Cancer: A Systematic Review and Meta-Analysis. Clin. Nucl. Med. 2013, 38, 305-314. [CrossRef] [PubMed]

96. Chiaravalloti, A.; Di Biagio, D.; Tavolozza, M.; Calabria, F.; Schillaci, O. PET/CT with 18F-choline after radical prostatectomy in patients with PSA $\leq 2 \mathrm{ng} / \mathrm{ml}$. Can PSA velocity and PSA doubling time help in patient selection? Eur. J. Nucl. Med. Mol. Imaging 2016, 43, 1418-1424. [CrossRef] [PubMed]

97. Graziani, T.; Ceci, F.; Castellucci, P.; Polverari, G.; Lima, G.M.; Lodi, F.; Morganti, A.G.; Ardizzoni, A.; Schiavina, R.; Fanti, S. 11C-Choline PET/CT for restaging prostate cancer. Results from 4,426 scans in a single-centre patient series. Eur. J. Nucl. Med. Mol. Imaging 2016, 43, 1971-1979. [CrossRef]

98. Silver, D.A.; Pellicer, I.; Fair, W.R.; Heston, W.D.; Cordon-Cardo, C. Prostate-specific membrane antigen expression in normal and malignant human tissues. Clin. Cancer Res. 1997, 3, 81-85.

99. Sweat, S.D.; Pacelli, A.; Murphy, G.P.; Bostwick, D.G. Prostate-specific membrane antigen expression is greatest in prostate adenocarcinoma and lymph node metastases. Urology 1998, 52, 637-640. [CrossRef]

100. Mannweiler, S.; Amersdorfer, P.; Trajanoski, S.; Terrett, J.A.; King, D.; Mehes, G. Heterogeneity of Prostate-Specific Membrane Antigen (PSMA) Expression in Prostate Carcinoma with Distant Metastasis. Pathol. Oncol. Res. 2009, 15, 167-172. [CrossRef]

101. Hövels, A.M.; Heesakkers, R.A.M.; Adang, E.M.; Jager, G.; Strum, S.; Hoogeveen, Y.; Severens, J.; Barentsz, J. The diagnostic accuracy of CT and MRI in the staging of pelvic lymph nodes in patients with prostate cancer: A meta-analysis. Clin. Radiol. 2008, 63, 387-395. [CrossRef]

102. Bakht, M.K.; Derecichei, I.; Li, Y.; Ferraiuolo, R.-M.; Dunning, M.J.; Oh, S.W.; Hussein, A.; Youn, H.; Stringer, K.F.; Jeong, C.W.; et al. Neuroendocrine differentiation of prostate cancer leads to PSMA suppression. Endocr.-Relat. Cancer 2019, 26, 131-146. [CrossRef] [PubMed]

103. Tan, N.; Bavadian, N.; Calais, J.; Oyoyo, U.; Kim, J.; Turkbey, I.B.; Mena, E.; Davenport, M.S. Imaging of Prostate Specific Membrane Antigen Targeted Radiotracers for the Detection of Prostate Cancer Biochemical Recurrence after Definitive Therapy: A Systematic Review and Meta-Analysis. J. Urol. 2019, 202, 231-240. [CrossRef] [PubMed]

104. Evans, J.D.; Jethwa, K.R.; Ost, P.; Williams, S.; Kwon, E.D.; Lowe, V.J.; Davis, B.J. Prostate cancer-specific PET radiotracers: A review on the clinical utility in recurrent disease. Pract. Radiat. Oncol. 2018, 8, 28-39. [CrossRef] [PubMed]

105. Tan, N.; Oyoyo, U.; Bavadian, N.; Ferguson, N.; Mukkamala, A.; Calais, J.; Davenport, M.S. PSMA-targeted Radiotracers versus ${ }^{18} \mathrm{~F}$ Fluciclovine for the Detection of Prostate Cancer Biochemical Recurrence after Definitive Therapy: A Systematic Review and Meta-Analysis. Radiology 2020, 296, 44-55. [CrossRef] 
106. Hope, T.A.; Goodman, J.Z.; Allen, I.E.; Calais, J.; Fendler, W.P.; Carroll, P.R. Metaanalysis of ${ }^{68}$ Ga-PSMA-11 PET Accuracy for the Detection of Prostate Cancer Validated by Histopathology. J. Nucl. Med. 2019, 60, 786-793. [CrossRef] [PubMed]

107. Ferraro, D.A.; Becker, A.S.; Kranzbühler, B.; Mebert, I.; Baltensperger, A.; Zeimpekis, K.G.; Grünig, H.; Messerli, M.; Rupp, N.J.; Rueschoff, J.H.; et al. Diagnostic performance of 68Ga-PSMA-11 PET/MRI-guided biopsy in patients with suspected prostate cancer: A prospective single-center study. Eur. J. Nucl. Med. Mol. Imaging 2021. [CrossRef]

108. Fendler, W.P.; Schmidt, D.F.; Wenter, V.; Thierfelder, K.M.; Zach, C.; Stief, C.; Bartenstein, P.; Kirchner, T.; Gildehaus, F.J.; Gratzke, C.; et al. 68Ga-PSMA PET/CT Detects the Location and Extent of Primary Prostate Cancer. J. Nucl. Med. 2016, 57, 1720-1725. [CrossRef]

109. Cytawa, W.; Seitz, A.K.; Kircher, S.; Fukushima, K.; Tran-Gia, J.; Schirbetl, A.; Bandurski, T.; Lass, P.; Krebs, M.; Połom, W.; et al. 68Ga-PSMA I\&T PET/CT for primary staging of prostate cancer. Eur. J. Nucl. Med. Mol. Imaging 2020, 47, 168-177. [CrossRef]

110. Ma, T.M.; Gafita, A.; Shabsovich, D.; Juarez, J.; Grogan, T.R.; Thin, P.; Armstrong, W.; Sonni, I.; Nguyen, K.; Lok, V.; et al. Identifying the Best Candidates for Prostate-specific Membrane Antigen Positron Emission Tomography/Computed Tomography as the Primary Staging Approach among Men with High-risk Prostate Cancer and Negative Conventional Imaging. Eur. Urol. Oncol. 2021. [CrossRef]

111. Fendler, W.P.; Calais, J.; Eiber, M.; Flavell, R.R.; Mishoe, A.; Feng, F.Y.; Nguyen, H.G.; Reiter, R.E.; Rettig, M.B.; Okamoto, S.; et al. Assessment of ${ }^{68}$ Ga-PSMA-11 PET Accuracy in Localizing Recurrent Prostate Cancer: A Prospective Single-Arm Clinical Trial. JAMA Oncol. 2019, 5, 856. [CrossRef]

112. Calais, J.; Ceci, F.; Eiber, M.; Hope, T.A.; Hofman, M.S.; Rischpler, C.; Bach-Gansmo, T.; Nanni, C.; Savir-Baruch, B.; Elashoff, D.; et al. 18F-fluciclovine PET-CT and 68Ga-PSMA-11 PET-CT in patients with early biochemical recurrence after prostatectomy: A prospective, single-centre, single-arm, comparative imaging trial. Lancet Oncol. 2019, 20, 1286-1294. [CrossRef]

113. Fendler, W.P.; Ferdinandus, J.; Czernin, J.; Eiber, M.; Flavell, R.R.; Behr, S.C.; Wu, I.-W.K.; Lawhn-Heath, C.; Pampaloni, M.H.; Reiter, R.E.; et al. Impact of ${ }^{68}$ Ga-PSMA-11 PET on the Management of Recurrent Prostate Cancer in a Prospective Single-Arm Clinical Trial. J. Nucl. Med. 2020, 61, 1793-1799. [CrossRef]

114. Hofman, M.S.; Lawrentschuk, N.; Francis, R.J.; Tang, C.; Vela, I.; Thomas, P.; Rutherford, N.; Martin, J.M.; Frydenberg, M.; Shakher, R.; et al. Prostate-specific membrane antigen PET-CT in patients with high-risk prostate cancer before curative-intent surgery or radiotherapy (proPSMA): A prospective, randomised, multicentre study. Lancet 2020, 395, 1208-1216. [CrossRef]

115. Rowe, S.P.; Macura, K.J.; Mena, E.; Blackford, A.L.; Nadal, R.; Antonarakis, E.S.; Eisenberger, M.; Carducci, M.; Fan, H.; Dannals, R.F.; et al. PSMA-Based [18F]DCFPyL PET/CT Is Superior to Conventional Imaging for Lesion Detection in Patients with Metastatic Prostate Cancer. Mol. Imaging Biol. 2016, 18, 411-419. [CrossRef]

116. Kelly, J.; Amor-Coarasa, A.; Nikolopoulou, A.; Kim, D.; Williams, C.; Ponnala, S.; Babich, J.W. Synthesis and pre-clinical evaluation of a new class of high-affinity 18F-labeled PSMA ligands for detection of prostate cancer by PET imaging. Eur. J. Nucl. Med. Mol. Imaging 2017, 44, 647-661. [CrossRef] [PubMed]

117. Cardinale, J.; Schäfer, M.; Benešová, M.; Bauder-Wüst, U.; Leotta, K.; Eder, M.; Neels, O.C.; Haberkorn, U.; Giesel, F.L.; Kopka, K. Preclinical Evaluation of ${ }^{18}$ F-PSMA-1007, a New Prostate-Specific Membrane Antigen Ligand for Prostate Cancer Imaging. J. Nucl. Med. 2017, 58, 425-431. [CrossRef] [PubMed]

118. Harada, N.; Kimura, H.; Onoe, S.; Watanabe, H.; Matsuoka, D.; Alrimitsu, K.; Ono, M.; Saji, H. Synthesis and Biologic Evaluation of Novel 18F-Labeled Probes Targeting Prostate-Specific Membrane Antigen for PET of Prostate Cancer. J. Nucl. Med. 2016, 57, 1978-1984. [CrossRef]

119. Jones, W.; Griffiths, K.; Barata, P.C.; Paller, C.J. PSMA Theranostics: Review of the Current Status of PSMA-Targeted Imaging and Radioligand Therapy. Cancers 2020, 12, 1367. [CrossRef]

120. Hofman, M.S.; Violet, J.; Hicks, R.J.; Ferdinandus, J.; Thang, S.P.; Akhurst, T.; Iravani, A.; Kong, G.; Kumar, A.R.; Murphy, D.G.; et al. [177 Lu]-PSMA-617 radionuclide treatment in patients with metastatic castration-resistant prostate cancer (LuPSMA trial): A single-centre, single-arm, phase 2 study. Lancet Oncol. 2018, 19, 825-833. [CrossRef]

121. Hofman, M.S.; Emmett, L.; Sandhu, S.; Iravani, A.; Joshua, A.M.; Goh, J.C.; Pattison, D.A.; Tan, T.H.; Kirkwood, I.D.; Ng, S.; et al. [177Lu]Lu-PSMA-617 versus cabazitaxel in patients with metastatic castration-resistant prostate cancer (TheraP): A randomised, open-label, phase 2 trial. Lancet 2021, 397, 797-804. [CrossRef]

122. Ceci, F.; Oprea-Lager, D.E.; Emmett, L.; Adam, J.A.; Bomanji, J.; Czernin, J.; Eiber, M.; Haberkorn, U.; Hofman, M.S.; Hope, T.A.; et al. E-PSMA: The EANM standardized reporting guidelines v1.0 for PSMA-PET. Eur. J. Nucl. Med. Mol. Imaging 2021. [CrossRef]

123. Chiro, G.D. Positron Emission Tomography Using [18F] Fluorodeoxyglucose in Brain Tumors A Powerful Diagnostic and Prognostic Tool. Investig. Radiol. 1987, 22, 360-371. [CrossRef] [PubMed]

124. Vander Heiden, M.G.; Cantley, L.C.; Thompson, C.B. Understanding the Warburg Effect: The Metabolic Requirements of Cell Proliferation. Science 2009, 324, 1029-1033. [CrossRef]

125. Farwell, M.D.; Pryma, D.A.; Mankoff, D.A. PET/CT imaging in cancer: Current applications and future directions: PET-CT Imaging in Cancer. Cancer 2014, 120, 3433-3445. [CrossRef] [PubMed]

126. Hanahan, D.; Weinberg, R.A. Hallmarks of Cancer: The Next Generation. Cell 2011, 144, 646-674. [CrossRef]

127. West, H. Immune Checkpoint Inhibitors. JAMA Oncol. 2015, 1, 115. [CrossRef] [PubMed]

128. Binnewies, M.; Roberts, E.W.; Kersten, K.; Chan, V.; Fearon, D.F.; Merad, M.; Coussens, L.M.; Gabrilovich, D.I.; Ostrand-Rosenberg, S.; Hedrick, C.C.; et al. Understanding the tumor immune microenvironment (TIME) for effective therapy. Nat. Med. 2018, 24, 541-550. [CrossRef] 
129. Haslam, A.; Prasad, V. Estimation of the Percentage of US Patients With Cancer Who Are Eligible for and Respond to Checkpoint Inhibitor Immunotherapy Drugs. JAMA Netw. Open 2019, 2, e192535. [CrossRef]

130. Valero, C.; Lee, M.; Hoen, D.; Zehir, A.; Berger, M.F.; Seshan, V.E.; Chan, T.A.; Morris, L.G.T. Response Rates to Anti-PD-1 Immunotherapy in Microsatellite-Stable Solid Tumors with 10 or More Mutations per Megabase. JAMA Oncol. 2021. [CrossRef]

131. Haslam, A.; Gill, J.; Prasad, V. Estimation of the Percentage of US Patients With Cancer Who Are Eligible for Immune Checkpoint Inhibitor Drugs. JAMA Netw. Open 2020, 3, e200423. [CrossRef] [PubMed]

132. Datta, M.; Coussens, L.M.; Nishikawa, H.; Hodi, F.S.; Jain, R.K. Reprogramming the Tumor Microenvironment to Improve Immunotherapy: Emerging Strategies and Combination Therapies. Am. Soc. Clin. Oncol. Educ. Book 2019, 39, 165-174. [CrossRef] [PubMed]

133. Popel, A.S. Immunoactivating the tumor microenvironment enhances immunotherapy as predicted by integrative computational model. Proc. Natl. Acad. Sci. USA 2020, 117, 4447-4449. [CrossRef] [PubMed]

134. Bouleau, A.; Lebon, V.; Truillet, C. PET imaging of immune checkpoint proteins in oncology. Pharmacol. Ther. 2021, 222, 107786. [CrossRef] [PubMed]

135. Bensch, F.; van der Veen, E.L.; Lub-de Hooge, M.N.; Jorritsma-Smit, A.; Boellaard, R.; Kok, I.C.; Oosting, S.F.; Schröder, C.P.; Hiltermann, T.J.N.; Van Der Wekken, A.J.; et al. 89Zr-atezolizumab imaging as a non-invasive approach to assess clinical response to PD-L1 blockade in cancer. Nat. Med. 2018, 24, 1852-1858. [CrossRef]

136. Niemeijer, A.N.; Leung, D.; Huisman, M.C.; Bahce, I.; Hoekstra, O.S.; Van Dongen, G.A.M.S.; Boellaard, R.; Du, S.; Hayes, W.; Smith, R.; et al. Whole body PD-1 and PD-L1 positron emission tomography in patients with non-small-cell lung cancer. Nat. Commun. 2018, 9, 4664. [CrossRef]

137. Loktev, A.; Lindner, T.; Mier, W.; Debus, J.; Altmann, A.; Jäger, D.; Giesel, F.; Kratochwil, C.; Barthe, P.; Roumestand, C.; et al. A Tumor-Imaging Method Targeting Cancer-Associated Fibroblasts. J. Nucl. Med. 2018, 59, 1423-1429. [CrossRef]

138. Giesel, F.L.; Kratochwil, C.; Lindner, T.; Marschalek, M.M.; Loktev, A.; Lehnert, W.; Debus, J.; Jäger, D.; Flechsig, P.; Altmann, A.; et al. ${ }^{68} \mathrm{Ga}$-FAPI PET/CT: Biodistribution and Preliminary Dosimetry Estimate of 2 DOTA-Containing FAP-Targeting Agents in Patients with Various Cancers. J. Nucl. Med. 2019, 60, 386-392. [CrossRef]

139. Kratochwil, C.; Flechsig, P.; Lindner, T.; Abderrahim, L.; Altmann, A.; Mier, W.; Adeberg, S.; Rathke, H.; Röhrich, M.; Winter, H.; et al. ${ }^{68}$ Ga-FAPI PET/CT: Tracer Uptake in 28 Different Kinds of Cancer. J. Nucl. Med. 2019, 60, 801-805. [CrossRef]

140. Barrett, R.L.; Puré, E. Cancer-associated fibroblasts and their influence on tumor immunity and immunotherapy. eLife 2020, 9 , e57243. [CrossRef] [PubMed]

141. Chen, X.; Song, E. Turning foes to friends: Targeting cancer-associated fibroblasts. Nat. Rev. Drug Discov. 2019, 18, 99-115. [CrossRef] [PubMed]

142. Chen, H.; Zhao, L.; Ruan, D.; Pang, Y.; Hao, B.; Dai, Y.; Wu, X.; Guo, W.; Fan, C.; Wu, J.; et al. Usefulness of [68Ga]Ga-DOTA-FAPI$04 \mathrm{PET} / \mathrm{CT}$ in patients presenting with inconclusive [18F]FDG PET/CT findings. Eur. J. Nucl. Med. Mol. Imaging 2021, $48,73-86$. [CrossRef]

143. Zhao, L.; Chen, S.; Chen, S.; Pang, Y.; Dai, Y.; Hu, S.; Lin, L.; Fu, L.; Sun, L.; Wu, H.; et al. 68Ga-fibroblast activation protein inhibitor PET/CT on gross tumour volume delineation for radiotherapy planning of oesophageal cancer. Radiother. Oncol. 2021, 158, 55-61. [CrossRef] [PubMed]

144. Watabe, T.; Liu, Y.; Kaneda-Nakashima, K.; Shirakami, Y.; Lindner, T.; Ooe, K.; Toyoshima, A.; Nagata, K.; Shimosegawa, E.; Haberkorn, U.; et al. Theranostics Targeting Fibroblast Activation Protein in the Tumor Stroma: ${ }^{64} \mathrm{Cu}-$ and ${ }^{225}$ Ac-Labeled FAPI-04 in Pancreatic Cancer Xenograft Mouse Models. J. Nucl. Med. 2020, 61, 563-569. [CrossRef] [PubMed]

145. Meyer, C.; Dahlbom, M.; Lindner, T.; Vauclin, S.; Mona, C.; Slavik, R.; Czernin, J.; Haberkorn, U.; Calais, J. Radiation Dosimetry and Biodistribution of ${ }^{68}$ Ga-FAPI-46 PET Imaging in Cancer Patients. J. Nucl. Med. 2020, 61, 1171-1177. [CrossRef]

146. Gerlinger, M.; Rowan, A.J.; Horswell, S.; Larkin, J.; Endesfelder, D.; Gronroos, E.; Martinez, P.; Matthews, N.; Stewart, A.; Tarpey, P.; et al. Intratumor Heterogeneity and Branched Evolution Revealed by Multiregion Sequencing. N. Engl. J. Med. 2012, 366, 883-892. [CrossRef]

147. Easwaran, H.; Tsai, H.-C.; Baylin, S.B. Cancer Epigenetics: Tumor Heterogeneity, Plasticity of Stem-like States, and Drug Resistance. Mol. Cell 2014, 54, 716-727. [CrossRef]

148. Tirkes, T.; Hollar, M.A.; Tann, M.; Kohli, M.D.; Akisik, F.; Sandrasegaran, K. Response criteria in oncologic imaging: Review of traditional and new criteria. Radiographics 2013, 33, 1323-1341. [CrossRef] [PubMed]

149. Borcoman, E.; Kanjanapan, Y.; Champiat, S.; Kato, S.; Servois, V.; Kurzrock, R.; Goel, S.; Bedard, P.; Le Tourneau, C. Novel patterns of response under immunotherapy. Ann. Oncol. 2019, 30, 385-396. [CrossRef] [PubMed]

150. Lambin, P.; Rios-Velazquez, E.; Leijenaar, R.; Carvalho, S.; van Stiphout, R.G.; Granton, P.; Zegers, C.M.; Gillies, R.; Boellard, R.; Dekker, A.; et al. Radiomics: Extracting more information from medical images using advanced feature analysis. Eur. J. Cancer 2012, 48, 441-446. [CrossRef]

151. O'Sullivan, F. A statistical measure of tissue heterogeneity with application to 3D PET sarcoma data. Biostatistics 2003, 4, 433-448. [CrossRef]

152. El Naqa, I.; Grigsby, P.W.; Apte, A.; Kidd, E.; Donnelly, E.; Khullar, D.; Chaudhari, S.; Yang, D.; Schmitt, M.; Laforest, R.; et al. Exploring feature-based approaches in PET images for predicting cancer treatment outcomes. Pattern Recognit. 2009, 42, 1162-1171. [CrossRef] 
153. Pinto dos Santos, D.; Dietzel, M.; Baessler, B. A decade of radiomics research: Are images really data or just patterns in the noise? Eur. Radiol. 2021, 31, 1-4. [CrossRef]

154. Yip, S.S.F.; Aerts, H.J.W.L. Applications and limitations of radiomics. Phys. Med. Biol. 2016, 61, R150-R166. [CrossRef] [PubMed]

155. Traverso, A.; Wee, L.; Dekker, A.; Gillies, R. Repeatability and Reproducibility of Radiomic Features: A Systematic Review. Int. J. Radiat. Oncol. Biol. Phys. 2018, 102, 1143-1158. [CrossRef] [PubMed]

156. Zwanenburg, A.; Vallières, M.; Abdalah, M.A.; Aerts, H.J.W.L.; Andrearczyk, V.; Apte, A.; Ashrafinia, S.; Bakas, S.; Beukinga, R.J.; Boellaard, R.; et al. The Image Biomarker Standardization Initiative: Standardized Quantitative Radiomics for High-Throughput Image-based Phenotyping. Radiology 2020, 295, 328-338. [CrossRef] [PubMed]

157. Mayo, C.S.; Kessler, M.L.; Eisbruch, A.; Weyburne, G.; Feng, M.; Hayman, J.A.; Jolly, S.; El Naqa, I.; Moran, J.M.; Matuszak, M.M.; et al. The big data effort in radiation oncology: Data mining or data farming? Adv. Radiat. Oncol. 2016, 1, 260-271. [CrossRef]

158. Orlhac, F.; Boughdad, S.; Philippe, C.; Stalla-Bourdillon, H.; Nioche, C.; Champion, L.; Soussan, M.; Frouin, F.; Frouin, V.; Buvat, I. A Postreconstruction Harmonization Method for Multicenter Radiomic Studies in PET. J. Nucl Med. 2018, 59, 1321-1328. [CrossRef]

159. Da-Ano, R.; Visvikis, D.; Hatt, M. Harmonization strategies for multicenter radiomics investigations. Phys. Med. Biol. 2020, 65, 24TR02. [CrossRef]

160. Chalkidou, A.; O’Doherty, M.J.; Marsden, P.K. False Discovery Rates in PET and CT Studies with Texture Features: A Systematic Review. PLoS ONE 2015, 10, e0124165. [CrossRef]

161. Collins, G.S.; Reitsma, J.B.; Altman, D.G.; Moons, K. Transparent reporting of a multivariable prediction model for individual prognosis or diagnosis (TRIPOD): The TRIPOD Statement. BMC Med. 2015, 13. [CrossRef]

162. Chicco, D. Ten quick tips for machine learning in computational biology. Biodata Min. 2017, 10, 35. [CrossRef] [PubMed]

163. Padhani, A.R.; Miles, K.A. Multiparametric Imaging of Tumor Response to Therapy. Radiology 2010, 256, 348-364. [CrossRef] [PubMed]

164. O'Connor, J.P.B.; Rose, C.J.; Waterton, J.C.; Carano, R.A.D.; Parker, G.J.M.; Jackson, A. Imaging intratumor heterogeneity: Role in therapy response, resistance, and clinical outcome. Clin. Cancer Res. 2015, 21, 249-257. [CrossRef] [PubMed]

165. Vallières, M.; Freeman, C.R.; Skamene, S.R.; El Naqa, I. A radiomics model from joint FDG-PET and MRI texture features for the prediction of lung metastases in soft-tissue sarcomas of the extremities. Phys. Med. Biol. 2015, 60, 5471-5496. [CrossRef] [PubMed]

166. Mu, W.; Tunali, I.; Gray, J.E.; Qi, J.; Schabath, M.B.; Gillies, R.J. Radiomics of 18F-FDG PET/CT images predicts clinical benefit of advanced NSCLC patients to checkpoint blockade immunotherapy. Eur. J. Nucl. Med. Mol. Imaging 2020, 47, 1168-1182. [CrossRef] [PubMed]

167. Delso, G.; Furst, S.; Jakoby, B.; Ladebeck, R.; Ganter, C.; Nekolla, S.G.; Schwaiger, M.; Ziegler, S.I. Performance Measurements of the Siemens mMR Integrated Whole-Body PET/MR Scanner. J. Nucl. Med. 2011, 52, 1914-1922. [CrossRef]

168. Besson, F.L.; Fernandez, B.; Faure, S.; Mercier, O.; Seferian, A.; Mignard, X.; Mussot, S.; Le Pechoux, C.; Caramella, C.; Botticella, A.; et al. 18F-FDG PET and DCE kinetic modeling and their correlations in primary NSCLC: First voxel-wise correlative analysis of human simultaneous [18F] FDG PET-MRI data. EJNMMI Res. 2020, 10, 88. [CrossRef]

169. Ypsilantis, P.-P.; Siddique, M.; Sohn, H.-M.; Davies, A.; Cook, G.; Goh, V.; Montana, G. Predicting Response to Neoadjuvant Chemotherapy with PET Imaging Using Convolutional Neural Networks. PLoS ONE 2015, 10, e0137036. [CrossRef]

170. Wang, H.; Zhou, Z.; Li, Y.; Chen, Z.; Lu, P.; Wang, W.; Liu, W.; Yu, L. Comparison of machine learning methods for classifying mediastinal lymph node metastasis of non-small cell lung cancer from 18F-FDG PET/CT images. EJNMMI Res. 2017, 7, 11. [CrossRef]

171. Sibille, L.; Seifert, R.; Avramovic, N.; Vehren, T.; Spottiswoode, B.; Zuehlsdorff, S.; Schäfers, M. ${ }^{18}$ F-FDG PET/CT Uptake Classification in Lymphoma and Lung Cancer by Using Deep Convolutional Neural Networks. Radiology 2020, $294,445-452$. [CrossRef] [PubMed]

172. Kawauchi, K.; Furuya, S.; Hirata, K.; Katoh, C.; Manabe, O.; Kobayashi, K.; Watanabe, S.; Shiga, T. A convolutional neural network-based system to classify patients using FDG PET/CT examinations. BMC Cancer 2020, 20, 227. [CrossRef]

173. Pinochet, P.; Eude, F.; Becker, S.; Shah, V.; Sibille, L.; Toledano, M.N.; Modzelewski, R.; Vera, P.; Decazes, P. Evaluation of an Automatic Classification Algorithm Using Convolutional Neural Networks in Oncological Positron Emission Tomography. Front. Med. 2021, 8, 628179. [CrossRef] [PubMed]

174. Guo, Z.; Li, X.; Huang, H.; Guo, N.; Li, Q. Deep Learning-Based Image Segmentation on Multimodal Medical Imaging. IEEE Trans. Radiat. Plasma Med. Sci. 2019, 3, 162-169. [CrossRef] 